\title{
E-Cadherin Regulates Neural Stem Cell Self-Renewal
}

\author{
Phillip Karpowicz, ${ }^{\star}$ Sandrine Willaime-Morawek, ${ }^{\star}$ Laurent Balenci, Brian DeVeale, Tomoyuki Inoue, and \\ Derek van der Kooy \\ Department of Molecular Genetics, University of Toronto, Toronto, Ontario, Canada M5S 1A8
}

E-Cadherin, a cell adhesion protein, has been shown to take part in the compartmentalization, proliferation, survival, and differentiation of cells. E-Cadherin is expressed in the adult and embryonic forebrain germinal zones in vivo, and in clonal colonies of cells derived from these regions and grown in vitro. Mice carrying E-Cadherin floxed genes crossed to mice expressing Cre under the Nestin promoter demonstrate defects in the self-renewal of neural stem cells both in vivo and in vitro. The functional role of E-Cadherin is further demonstrated using adhesion-blocking antibodies in vitro, which specifically target cadherin extracellular adhesive domains. Adult neural stem cell colonies decrease in the presence of E-Cadherin antibodies in a dosage-dependent manner, in contrast to P-Cadherin antibody. On overexpression of normal E-Cadherin and a mutated E-Cadherin, containing no intracellular binding domain, an increased number of clonal adult neural stem cell colonies are observed. These data suggest it is specifically E-Cadherin adhesion that is responsible for these self-renewal effects. These data show the importance of E-Cadherin in the neural stem cell niche and suggest E-Cadherin regulates the number of these cells.

\section{Introduction}

Stem cell (SC) behavior is of interest for its biological insights as well as its possible therapeutic utility. Neural stem cells (NSCs) (Alvarez-Buylla et al., 2001) are localized within the subependymal zone of the forebrain (Morshead and van der Kooy, 2001), a region that can be thought of as the NSC niche. The notion of a niche that influences SC maintenance has emerged as a compelling theory that explains certain SC characteristics (AlvarezBuylla and Lim, 2004; Ohlstein et al., 2004). Molecular factors that operate within and that comprise the SC niche are thought to determine cell behavior within that localized environment (Kai and Spradling, 2003), as well as to account for both the persistence of the SC in that environment throughout the lifetime of the animal.

Short-range factors in the niche might comprise a restricted microenvironment in which the division of SCs would produce daughter cells in drastically different contexts. Thus, by virtue of its slightly different position, the daughter retained in the niche might resume the same SC behavior as its parent, whereas the other would assume a different fate. Examples of such shortrange signals are gap junctions, which have been shown to influence the proliferation of neural progenitors (Cheng et al., 2004), and the Notch juxtacrine signaling pathway, which has general effects on neural development and specific effects on the mainte-

Received Jan. 5, 2009; revised Feb. 13, 2009; accepted Feb. 16, 2009.

This work was supported by the Natural Sciences and Engineering Research Council, Stem Cell Network/Juvenile Diabetes Research Foundation (to S.W.-M.), and Canadian Institutes of Health Research. We thank Drs. Elaine Fuchs and Rolf Kemler for sharing the E-Cadherin flox mouse strain, Dr. Rudiger Blindt for the N-Cadherin CDNA, and Dr. Seiji Hitoshi for the pMXIE and E-Cad-pMXIE retroviral constructs. As well, members of the van der Kooy Laboratory are thanked for their insightful comments.

*P.K. and S.W.-M. contributed equally to this work.

Correspondence should be addressed to Phillip Karpowicz at the above address. E-mail: phillip.karpowicz@utoronto.ca.

DOI:10.1523/JNEUROSCI.0037-09.2009

Copyright $\odot 2009$ Society for Neuroscience $\quad$ 0270-6474/09/293885-12\$15.00/0 nance of NSCs (Hitoshi et al., 2002; Campos et al., 2006; Louvi and Artavanis-Tsakonas, 2006).

One important aspect of the niche is the mechanism by which NSCs remain in the germinal zone. Candidates for anchoring these cells are cadherins, cell adhesion proteins that are thought to play a role in diverse tissues (Takeichi, 1995). It is currently understood that cadherins of the same type bind homophilically and drive cells to sort together to self-assemble into aggregates that maximize such homotypic adhesion events (Foty and Steinberg, 2005).Vertebrate cadherins are thought to be involved in the compartmentalization of different neural regions during development (Redies, 2000).

E-Cadherin is transiently expressed in the developing diencephalons and mesencephalon of mouse embryos (Shimamura and Takeichi, 1992) in which it is believed to participate in the segmentation of the developing brain (Matsunami and Takeichi, 1995). Although it is downregulated in most of the brain during embryogenesis, the expression of E-Cadherin is seen in the ventricles of the developing (Rasin et al., 2007) and adult brain (Kuo et al., 2006), regions in which NSCs reside and/or contact.

We examined the loss and gain of E-Cadherin in NSCs of the adult mouse brain. NSCs arise during development and are thought to contribute to neurogenesis in the embryo and the adult (Tropepe et al., 1999). Such NSCs can be characterized in vivo or in vitro using a clonal cell culture system in which single cells dissected from the adult or embryonic neural regions demonstrate both self-renewal and multipotentiality (Reynolds et al., 1992; Morshead et al., 1994; Tropepe et al., 1999). Our results show that E-Cadherin is expressed by NSCs and regulates NSC self-renewal in the murine forebrain.

\section{Materials and Methods}

Animal dissection and cell culture. E-Cadherin ${ }^{\text {floxed/+ }}$ (Boussadia et al., 2002) and Nestin-Cre [B6.Cg-Tg(Nes-cre) $1 \mathrm{Kln} / \mathrm{J}$; The Jackson Laboratory] mice were crossed to obtain a E-Cadherin floxed/+ ; Nestin-Cre strain 
that expresses Cre specifically in the nervous system. This was then backcrossed with E-Cadherin floxed/foxed to obtain the E-Cadherin floxed/floxed; Nestin-Cre strain $\left(\mathrm{Ecad}^{\Delta / \Delta}\right)$. E-Cadherin ${ }^{+/+} ;$Nestin-Cre offspring from these crosses were used as wild-type controls ( $\left.\mathrm{Ecad}^{\mathrm{Wt} / \mathrm{Wt}}\right)$. CD1 and B57 wild-type mice, Ecad ${ }^{\mathrm{Wt} / \mathrm{Wt}}$, and Ecad ${ }^{\Delta / \Delta}$ mice were dissected, and their NSCs were cultured as previously described (1) for embryonic day 9.5 (E9.5) and E13.5 embryonic forebrain ventricles (Tropepe et al., 1999) or (2) for adult mouse forebrain ventricles (Reynolds et al., 1992; Morshead et al., 1994). Cells were cultured at 10 cells/ $\mu$ l after dissection and passaged thereafter at 5 cells/ $\mu \mathrm{l}$ in all experiments. Neurospheres arising from Ecad ${ }^{\Delta / \Delta}$ were passaged exactly as wild types, and both were counted after $7 \mathrm{~d}$ in vitro. The number of spheres was $\sim 100-50$ per well for wild-type animals and one-half of this for the Ecad ${ }^{\Delta / \Delta}$ animals in the long-term passaging experiments. Antibodies against E-Cadherin (ECCD-1 and ECCD-2; Zymed), N-Cadherin (Sigma-Aldrich), or P-Cadherin (Zymed) were dissolved in water and added to media just before application, at the concentrations indicated in the text.

Plasmid construction and retroviral infection. The pMXIE retroviral construct has been described previously (Hitoshi et al., 2002). To generate the pMXIE-E-Cadherin construct, human E-cadherin cDNA was amplified by PCR in $50 \mu \mathrm{l}$ volume consisting of $1 \mu \mathrm{M}$ sense $\left(5^{\prime}\right.$ CCCTCGCTCGAGGTCCCCGGCCCAG- $\left.3^{\prime}\right)$ and antisense (5'CCTCTCTCGAGATCTCTAGTCGTCCTCG-3') primers, $2.5 \mathrm{~mm}$ $\mathrm{Mg}^{2+}, 0.3 \mathrm{~mm}$ dNTP, $1 \mu \mathrm{l}$ of Takara LA Taq polymerase (Takara), and pLKpac1 human E-Cadherin plasmid (a gift from Dr. A. B. Reynolds, Vanderbilt University, Nashville, TN) as a template. PCR parameters included the following: denaturation at $95^{\circ} \mathrm{C}$ for $30 \mathrm{~s}$, annealing at $60^{\circ} \mathrm{C}$ for $60 \mathrm{~s}$, and extension at $72^{\circ} \mathrm{C}$ for $180 \mathrm{~s}$ for 20 cycles. The amplified DNA fragments were digested with $X h o \mathrm{I}$ and BglII and ligated to the XhoI$B a m$ HI site of the pMXIE retroviral vector plasmid. To generate the pMXIE-N-Cadherin construct, the plasmid was first cut using XhoI and BamHI. An oligo containing the sites SalI-BamHI-XhoI-BglII, in that order, was digested with SalI and BglII. The cut products were ligated to modify the multiple cloning site of pMXIE to contain Bam HI, XhoI in the correct sequence, allowing for the insertion of the human $\mathrm{N}$-Cadherin cDNA (a gift from Dr. R. Blindt, University Hospital Aachen, Aachen, Germany) after its excision from the pCMX plasmid using BamHI and XhoI. A total of 100,000 cells was exposed to virus at a ratio of 10 virus particles to 1 cell in the presence of $5 \mathrm{ng} / \mu \mathrm{l}$ hexadimethrine bromide (Sigma-Aldrich). Cells were incubated with retrovirus in $250 \mu \mathrm{l}$ of cell culture media [containing EGF (epidermal growth factor) and FGF] for $90 \mathrm{~min}$ while being centrifuged at $1000 \mathrm{rpm}$ at room temperature. Cells were then resuspended, recounted, and plated as described above. Before use, colonies were examined to confirm retrovirus integration and transgene expression by fluorescence microscopy.

Immunocytochemistry/immunohistochemistry. Adult mice were anesthetized and perfused using $4 \%$ paraformaldehyde (Sigma-Aldrich) dissolved in cold Stockholm's PBS, pH 7.3. After perfusion, brains were dissected from cranium and fixed overnight at $4^{\circ} \mathrm{C}$ in $4 \%$ paraformaldehyde. Brains were then washed with Stockholm's and equilibrated in Stockholm's containing 30\% w/v sucrose (Sigma-Aldrich) at $4^{\circ} \mathrm{C}$. Samples were then embedded in cryoprotectant (Thermo Fisher Scientific) and sectioned on a Jencon's OTF5000 cryostat at 15 or $20 \mu \mathrm{m}$ thickness. NSC colonies were coated with Matrigel for $30 \mathrm{~min}$ at $37^{\circ} \mathrm{C}$. Cell attachment was assessed by gently tapping plates under the microscope. Cells were fixed using $4 \%$ paraformaldehyde (Sigma-Aldrich) dissolved in cold Stockholm's PBS, pH 7.3, for 15 min. Sections or colonies were washed three times for 10 min each time with Stockholm's PBS plus $0.3 \%$ Triton X-100 detergent (Sigma-Aldrich). To detect bromodeoxyuridine (BrdU), cells were exposed to $4 \mathrm{~N} \mathrm{HCl}$ for $30 \mathrm{~min}$. Samples were then blocked using $1 \%$ bovine serum albumin (Sigma-Aldrich) plus $10 \%$ normal goat serum (Sigma-Aldrich) in Stockholm's, pH 7.3, 0.3\% Triton X-100 (Sigma-Aldrich) for $60 \mathrm{~min}$ at room temperature. Primary antibodies were applied overnight in Stockholm's, 1.0\% NGS, 0.3\% Triton $\mathrm{X}$-100. $\alpha$-E-Cadherin (Millipore; 1:100), $\alpha$-N-Cadherin (GC-4; SigmaAldrich; 1:100), $\alpha$-BrdU Bu1/75 (Abcam; 1:500), $\alpha$-Nestin (Millipore Bioscience Research Reagents; 1:1000), $\alpha$ - $\beta$-tubulin isotype III (SigmaAldrich; 1:500), $\alpha$-pan-histone (Millipore Bioscience Research Reagents; 1:500), $\alpha$-CD-133 (eBioscience; 1:50), $\alpha$-polysialylated neural cell adhe- sion molecule (PSA-NCam) (Millipore Bioscience Research Reagents; 1:200), $\alpha$-Sox2 (Millipore Bioscience Research Reagents; 1:200), and $\alpha$-glial fibrillary acidic protein (Sigma-Aldrich; 1:400) were used. Samples were washed three times with Stockholm's and blocked again using the same conditions above. Secondary antibodies were applied at $37^{\circ} \mathrm{C}$ for $50 \mathrm{~min}$ (for colony immunocytochemistry) or $2 \mathrm{~h}$ (for section immunohistochemistry) in Stockholm's PBS, 1.0\% normal goat serum. TRITC (tetramethylrhodamine isothiocyanate)-, FITC-, or HRP-conjugated antibodies (Jackson ImmunoResearch Laboratories; 1:250) or 488, 568, $633 \mathrm{~nm}$ Alexa Fluor antibodies (Invitrogen; 1:300) were used as appropriate. Cadherin staining was enhanced by tyramide signal amplification (TSA Plus Cyanine 3/Fluorescein kit; PerkinElmer). Nuclei were counterstained with $10 \mu \mathrm{g} / \mathrm{ml}$ Hoechst 33258 (Sigma-Aldrich) or Topro-3 (Invitrogen). Sections were mounted and coverslipped using Gel Mount (Biomeda).

Microscopy. Photographs were taken under $40 \times / 0.55$ (dry lens) objective using a $40 \times / 0.60$ Olympus IX81 inverted microscope with the Olympus Microsuite, version 3.2, Analysis imaging system software (Soft Imaging Systems). Confocal micrographs were visualized and photographed using a Plan-Apochromat $60 \times / 1.40$ oil-immersion lens objective on a LSM510 (Carl Zeiss). Confocal sections of $<0.5 \mu \mathrm{m}$ thickness were taken. Detection settings were kept constant when comparing Ecad $^{\mathrm{Wt} / \mathrm{Wt}}$ versus Ecad ${ }^{\Delta / \Delta}$ samples; otherwise, these were adjusted as needed. All photos were processed using Adobe Photoshop CS2 software; images of Ecad ${ }^{\mathrm{Wt} / \mathrm{Wt}}$ versus Ecad ${ }^{\Delta / \Delta}$ were prepared identically.

Transmission electron microscopy. Nine-month-old wild-type and Ecadh $^{-1-}$ mice were anesthetized and perfused using $2.5 \%$ glutaraldehyde (Electron Microscopy Sciences) dissolved in Sorensen's phosphate buffer. Brains were then dissected out and fixed for $24 \mathrm{~h}$ at $4^{\circ} \mathrm{C}$ in the fixative solution mentioned above. Tissues were sectioned on a vibratome at $200 \mu \mathrm{m}$ and kept in fresh fixative solution for 3 more hours at $4^{\circ} \mathrm{C}$ and postfixed in $1 \%$ osmium tetroxide for $2 \mathrm{~h}$. Brain slices were then washed in Sorensen's phosphate buffer and dehydrated using a graded series of ethanol, 50, 70, and 95\%, twice each for $15 \mathrm{~min}$ followed by three baths of $100 \% \mathrm{EtOH}$, and samples were finally washed in propylene oxide (twice 15 min each). Thick sections were placed into polyethylene BEEM capsules, embedded in Epon Araldite resin, and kept at $60^{\circ} \mathrm{C}$ for $48 \mathrm{~h}$. After identification of the lateral ventricle and SEZ areas, samples were cut again, placed on resin blocks and then sectioned on a Reichert Ultracut E microtome to $90 \mathrm{~nm}$ thickness and collected on mesh copper grids (Electron Microscopy Sciences). Wild-type and conditional knockout sections were cut in parallel. Ultrathin sections were counterstained using saturated uranyl acetate for 15-20 min and electron-opaque stained in Reynold's lead citrate. EM pictures were captured with a Hitachi H7000 transmission electron microscope. A minimum of six sections was examined from each animal, and a total of 20 sections per genotype.

Fluorescence-activated cell sorting. Cells were sorted on FACS DiVa (BD Biosciences) system. Cells were sorted at $\sim 9000$ events per second, and fractions were kept on ice until plated. At the outset of each experiment, CD1 [green fluorescent protein (GFP)-negative] adult neurosphere cells and GFP transgenic adult neurosphere cells served as negative and positive controls, respectively, to set the gates for cell sorting. Fluorescence microscopy confirmed the positivity of retrovirus-infected cells just before use. Cells were dissociated mechanically and blocked for $30 \mathrm{~min}$ at $37^{\circ} \mathrm{C}$, in Dulbecco's PBS, pH 7.3, plus $10 \%$ normal goat serum (SigmaAldrich). Cells were then exposed to $2 \mu \mathrm{g} / \mathrm{ml}$ primary anti-E-Cadherin antibody ECCD2 (Zymed; 1:500), in $1 \mathrm{ml}$ of Dulbecco's plus 3\% goat serum for $1 \mathrm{~h}$ at $37^{\circ} \mathrm{C}$. Cells were then washed two times in $10 \mathrm{ml}$ of Dulbecco's and exposed to goat anti-mouse $633 \mathrm{~nm}$ Alexa Fluor antibody (Invitrogen; 1:300) for an additional hour in the same conditions as the primary. Cells were then washed two times in $10 \mathrm{ml}$ of Dulbecco's and sorted. Embryonic stem cells served as positive controls to confirm the efficacy of the E-Cadherin antibody.

Cell death detection. Terminal deoxynucleotidyl transferase-mediated biotinylated UTP nick end labeling (TUNEL) was performed using a Fluorescein In Situ Cell Death Detection kit (Roche Applied Science).

$P C R$ and reverse transcription-PCR. Tail clip DNA and mRNA were extracted using the DNeasy Tissue kit (QIAGEN) and RNeasy Mini/ 
Micro kits (QIAGEN), respectively. Genotyping was performed using the following primer sequences: Cdh1 forward, GAATTCTGAACATCATTATCAGTATTTA; reverse, TGACACATGCCTTTACTTTAGT; Cre forward, GCGGTCTGGCAGTAAAAACTATC; reverse, GTGAAACAGCATTGCTGTCACTT; IL2 forward, CTAGGCCACAGAATTGAAAGATCT; reverse, GTAGGTGGAAATTCTAGCATCATCC. Transcript detection was performed using one-step reverse transcription (RT) reactions in the RNeasy kits (QIAGEN), either on bulk cultures or single NSC colonies, with the following sequences: Cdh1/E-Cadherin, forward, CGTGATGAAGGTCTCAGCC; reverse, GATGGGGGCTTCATTCACG; Cdh2/N-Cadherin, forward, CCTGGAATGCGGCATAC; reverse, GAAGATCAAACGCGAACG; $\beta$-Catenin, forward, CATGTTCCCTGAGACGCTAGA; reverse, CAGAGTCCCAGCAGTACAACG; $\alpha$-Catenin, forward, TTTATCGCATCTGAAAATTGTCG; reverse, CTTGGTCATCTTGTCAATCGC; p120, forward, CACCATCAACGAAGTTATCGC; reverse, GCAGGTAGAGTGGCGCTAAA; Actin, forward, GAAGTGTGATGTGGATATCCGC; reverse, AGAAGCATTTGCGGTGGAC. Nested PCR on the Cdh1/E-Cadherin RT product was performed with the following sequences: forward, CAGACGATGACGTCAACAC; reverse, CCTCATTCTCAGGCACTTG.

Statistics. Analysis was performed using GraphPad Prism 4.0. Comparisons between samples were performed by unpaired $t$ tests; comparisons between multiple groups were performed by ANOVA with Dunnett's post test as required.

\section{Results}

\section{E-Cadherin is present in the adult and embryonic brain and in clonal stem cell colonies}

First, E-Cadherin transcript was probed in the adult forebrain germinal zones. We found E-Cadherin RNA, and that of its binding partners $\beta$-Catenin, $\alpha$-Catenin, and p120, present by RTPCR both in vivo and in clonal colonies in vitro derived from adult ventricle tissues (supplemental Table 1, available at www. jneurosci.org as supplemental material). Forebrain germinal zone cells from E9.5 and E13.5 embryos, as well as their respective colonies, also were found to express these same transcripts. $\mathrm{N}$-Cadherin expression, which is known to be present in neural tissues, was similarly confirmed in adult ventricular tissue and adult-derived colonies (supplemental Table 1, available at www. jneurosci.org as supplemental material).

Second, adult forebrain ventricles were assayed by immunohistochemistry to confirm the presence of E-Cadherin protein in the NSC niche. Consistent with published results by Kuo et al. (2006), E-Cadherin presence was confirmed in the ependymal cells of the ventricles as well as at low levels in the subependymal zone (Fig. $1 A$ ). N-Cadherin was shown to occupy a similar distribution in these very same regions (Fig. $1 B$ ). Dissection of adult ventricular zones followed by cellular dissociation, antibody staining, and flow cytometry confirmed that $4.2 \pm 0.8 \%$ of dissected adult forebrain germinal zone cells expressed the E-Cadherin protein (data not shown).

Antibody was next applied to the clonal colonies grown from NSCs dissected from germinal zones in the embryo or the adult. Immunocytochemistry showed the presence of E-Cad in clonal E9.5, E13.5, and adult neurosphere colonies (data not shown). Because Cadherins have been proposed to mediate cell sorting, we examined $7 \mathrm{~d}$ NSC neurospheres to determine whether E-Cad-positive cells demonstrated any localization within these (Fig. 1Ci). Although E-Cadherin-positive cells clustered together in these colonies, no complete separation between E-Cadherinpositive and -negative cells was observed in any of the colonies examined. This may be attributable to the presence of $\mathrm{N}$-Cadherin in these cells, which, when examined, showed expression throughout all cells in these colonies (Fig. 1Cii).

Together, these data show that RNA transcripts of E-Cadherin and its associated binding partners are found both in vivo and in the in vitro colonies derived from NSCs. The E-Cadherin protein is present in the adult brain and in SC-initiated colonies derived from different developmental time points. However, E-Cadherin alone does not appear to mediate complete sorting out (Steinberg and Takeichi, 1994) between E-Cadherin-positive and -negative neural cells arising from NSCs in vitro.

\section{Disruption of E-Cadherin in vivo reduces NSC self-renewal but increases neural progenitor proliferation}

Previous studies have shown that neurogenesis is impaired in mutations of the adherens junction protein $\alpha$-E-Catenin (Lien et al., 2006). In contrast, neurogenesis appears normal in mutants of the protein aPKC $\lambda$ (atypical protein kinase $C \lambda$ ), which is thought to regulate the formation of adherens junctions (Imai et al., 2006). These studies presumably affected adherens junctions throughout the nervous system. We attempted to focus on mutations of E-Cadherin in areas in which NSCs specifically reside, because E-Cadherin expression seems localized to ventricular regions of the adult forebrain (Kuo et al., 2006; Rasin et al., 2007). E-Cadherin-null embryos are not viable (Larue et al., 1994), and thus the role of this protein cannot be examined in the adult brain using conventional mutants. E-Cadherin conditional knock-outs were assayed by crossing mice carrying LoxP sites in introns 5 and 10 of the E-Cadherin gene (Boussadia et al., 2002) with mice expressing the Cre-recombinase enzyme under the Nestin promoter (Tronche et al., 1999). Given that all of these tissues derive from Nestin-expressing precursors, this cross should result in the deletion of functional E-Cadherin protein in all CNS tissues. The efficient excision of genomic E-Cadherin was confirmed by PCR (Fig. $1 D$ ) and by immunohistochemistry (Fig. $1 A$ ). It was noted that $\mathrm{N}$-Cadherin expression and localization was normal on deletion of E-Cadherin (Fig. 1B).

Conditional E-Cadherin mutant mice $\left(\operatorname{Ecad}^{\Delta / \Delta}\right.$ mice) obtained from these crosses did not seem abnormal in appearance or behavior. Indeed, no phenotypes were readily observed in adult $\operatorname{Ecad}^{\Delta / \Delta}$ brains, suggesting that any transient effects of E-Cadherin expression in the embryonic and adult brain are negligible or compensated for during development. We examined cell proliferation in the forebrain ventricles of 2-month-old mice by BrdU uptake $1 \mathrm{~h}$ after administration (Fig. $2 A$ ). Ecad $^{\Delta / \Delta}$ mice were noted to have an increased number of cells in S-phase compared with their littermate wild-type $\left(\right.$ Ecad $\left.^{\mathrm{Wt} / \mathrm{Wt}}\right)$ controls during this time of early adulthood. However, because NSCs are a minority of the cells in this region, it is most likely that this difference is attributable to the progenitors residing in these tissues. NSCs themselves are thought to divide relatively slowly and their presence can be distinguished from that of fast-dividing adjacent neural progenitor cells by assaying long-term BrdU retention among cells in these regions (Morshead et al., 1998). The longterm retention of BrdU was examined to resolve between NSCs and neural progenitors in the forebrain ventricles. We did not observe any differences in the numbers of BrdU-retaining cells between 2-month-old Ecad ${ }^{\Delta / \Delta}$ and Ecad ${ }^{\mathrm{Wt} / \mathrm{Wt}}$ mice, 1 month after five BrdU injections administered every $3 \mathrm{~h}$ over $15 \mathrm{~h}$ total (Fig. 2A). These data suggested that neural progenitor proliferation was accelerated in the absence of E-Cadherin, but NSC numbers were normal with or without the protein.

We sought to determine whether an age-dependent effect of E-Cadherin became apparent during neurogenesis at later time points during adulthood. Animals were aged to 9 month time point and neural cell proliferation was assessed in the Ecad ${ }^{\Delta / \Delta}$ after the same short-term, $1 \mathrm{~h}$ BrdU pulse. Aged SVZ cells from 

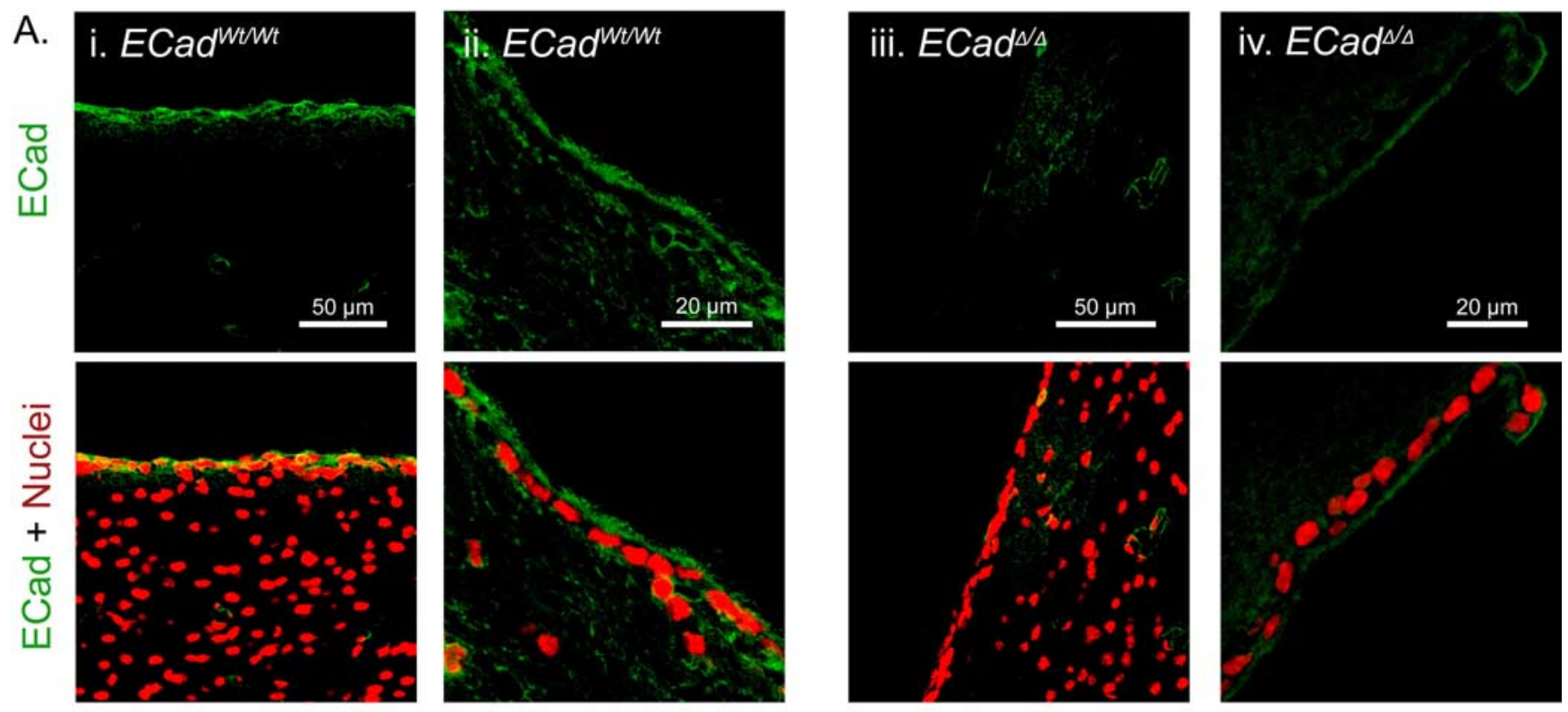

B.
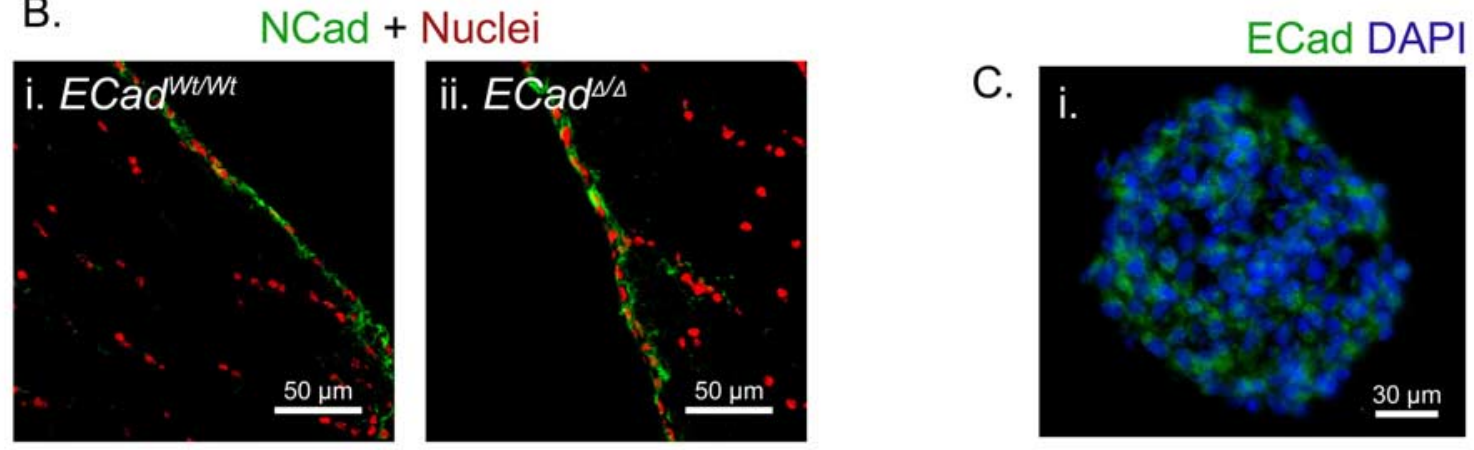

D.
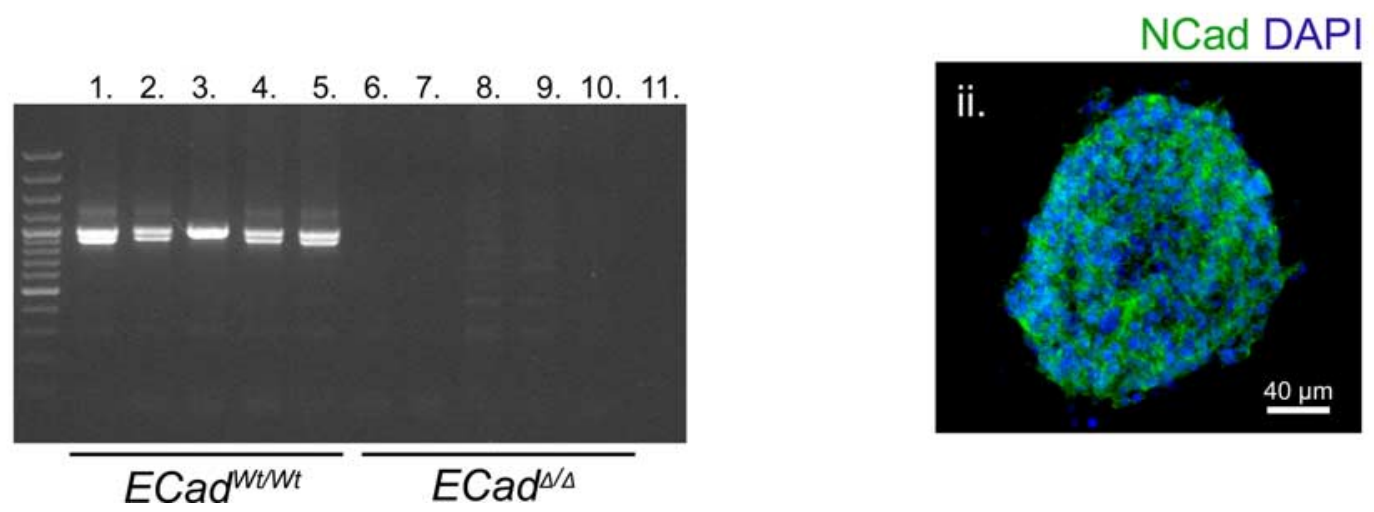

Figure 1. A, E-Cadherin is expressed in the adult murine ventricles. Image shows confocal micrographs of E-Cadherin in the adult forebrain lateral ventricular germinal zone (green). E-Cadherin stains primarily in ependymal cells and to a lesser extent in subependymal cells in wild-type animals (i, ii) versus conditional knock-outs (iii, iv), whose E-Cadherin staining is almost completely absent. Nuclei are shown in merge in red. $\boldsymbol{B}, \mathrm{N}$-Cadherin is expressed in the adult murine ventricles. The image shows confocal micrographs of $\mathrm{N}$-Cadherin in the forebrain lateral ventricular germinal zone (green). Similar to E-Cadherin, N-Cadherin staining is seen particularly in the ependymal cells rather than subependymal cells. Both E-Cadherin wild type (i) and conditional knock-outs (ii) display N-Cadherin in these regions. Nuclei are shown in merge in red. C, E-Cadherin and N-Cadherin are expressed at day 7 in vitro in adult NSC colonies. Merged images show sections of large NSC colonies stained for E-Cadherin (green; $i$ ) and N-Cadherin (green; ii). DAPI (4' 6-diamidino-2-phenylindole) counterstain is blue. N-Cadherin staining was noted to be stronger and more widely expressed than E-Cadherin in these colonies. D, E-Cadherin PCR of colonies derived from NSCs dissected from adult forebrain ventricles. Image shows complete loss of E-Cadherin PCR product in wild-type ( $n=5$ animals; rows $1-5$ ) versus conditional knock-out animals $(n=5$ animals; rows $6-10)$. DNA was extracted from passage 2 NSC colonies to avoid contamination from endothelial cells, also present in the SVZ, which express E-Cadherin protein. Because primers span intron 10 of the E-Cadherin gene, the larger band indicates alleles in which a loxP site is present. The lower bands show wild-type allele. Row 11 is negative (water) control.

Ecad $^{\Delta / \Delta}$ mice also showed increased cell proliferation compared with wild-type Ecad ${ }^{\mathrm{Wt} / \mathrm{Wt}}$ controls showing that the effect of $\mathrm{E}$-Cad loss is a lifelong increase in cell division of cells in the forebrain germinal zone (Fig. $2 B-D$ ). However, in contrast to young 2-month-old mice, aged 9-month-old Ecad ${ }^{\Delta / \Delta}$ mice had a significant decrease in BrdU-retaining cells in the subependymal zone (Fig. 2D). These results suggest that E-Cadherin functions to restrict neural progenitor divisions in the neurogenic adult 
A.
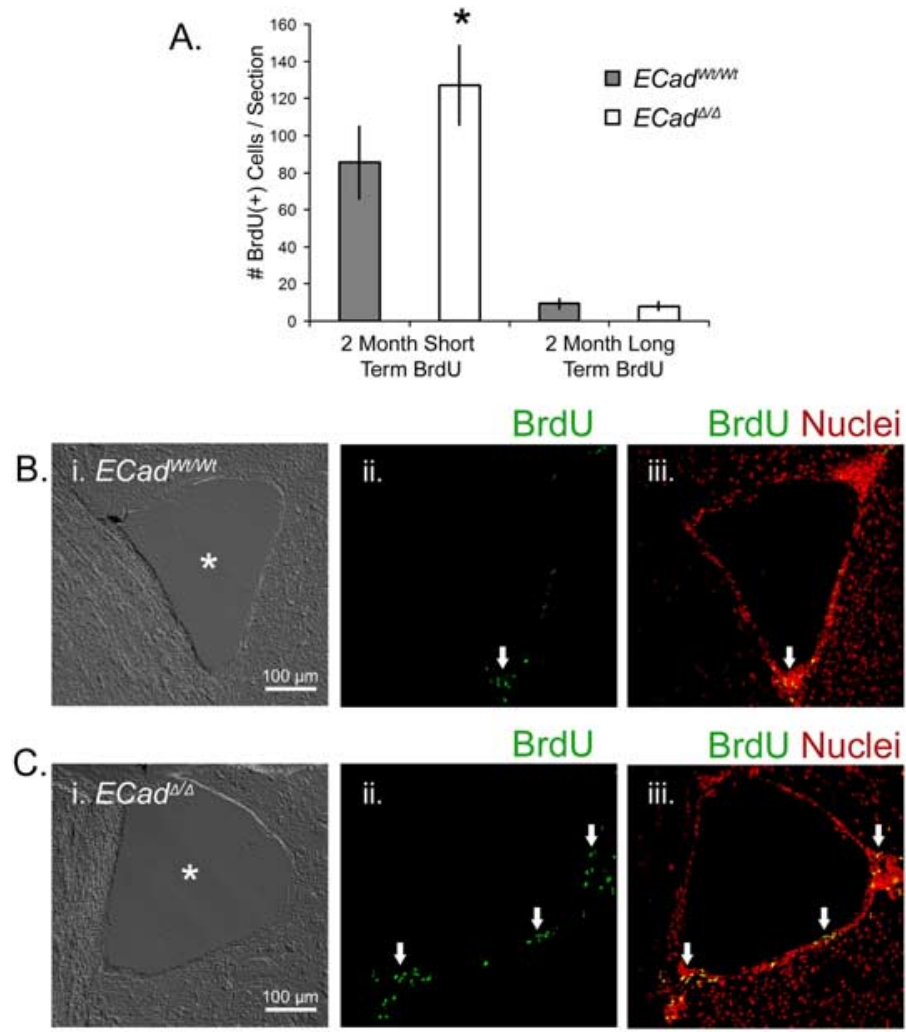

D.

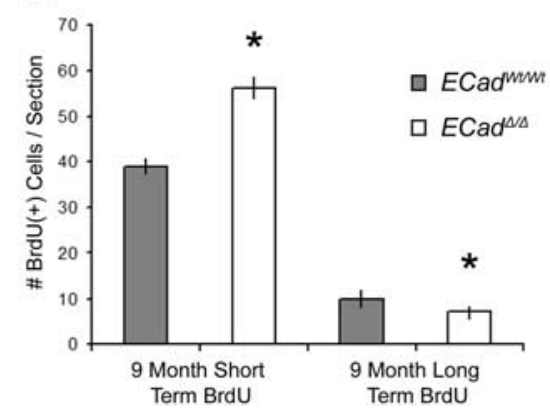

E.

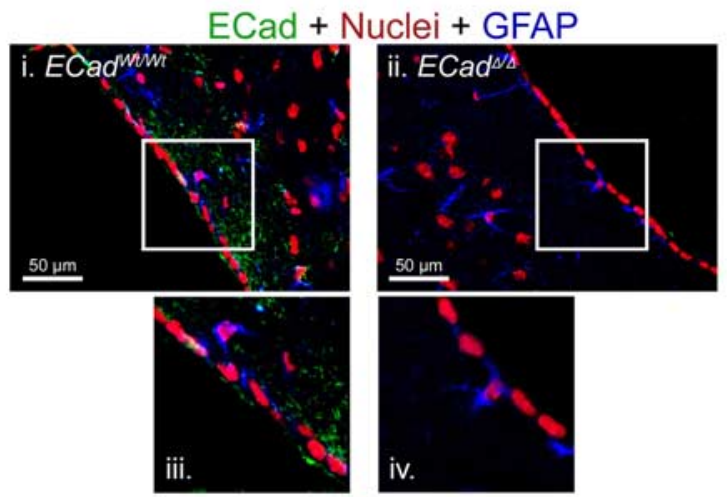

F.

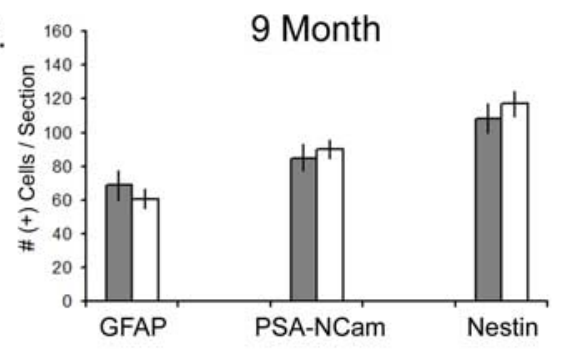

$\square$ ECad ${ }^{m m}$

$\square \mathrm{ECad}^{\mathrm{N} / \mathrm{\Delta}}$

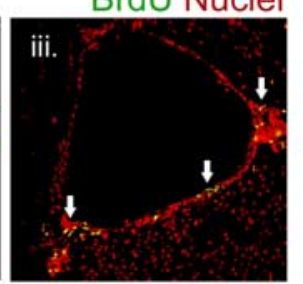

G.

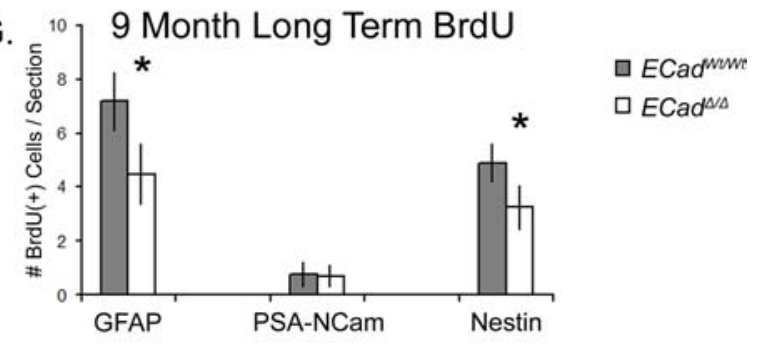

Figure 2. A, BrdU uptake is increased but BrdU retention is equivalent, in 2 month E-Cadherin conditional knock-out forebrain ventricular subependyma. Left, The graph shows an increase in $\mathrm{BrdU}^{+}$progenitors in $\mathrm{Ecad}^{\Delta / \Delta}$ mice $(n=3)$ compared with their Ecad ${ }^{\mathrm{Wt} / \mathrm{Wt}}$ littermate controls $(n=3)$ at 2 months of age. The asterisk indicates that the difference is significant $(t=4.529 ; \mathrm{df}=$ $58 ; p<0.05)$. Right, Same graph shows numbers of BrdU ${ }^{+}$nuclei in 2-month-old BrdU ${ }^{+}$retaining progenitors, 1 month after BrdU injection, in Ecad ${ }^{\Delta / \Delta}$ mice $(n=3)$ compared with their $\mathrm{Ecad}^{\mathrm{Wt} / \mathrm{Wt}}$ littermate controls $(n=3)$. There are no significant differences. $\boldsymbol{B}$, BrdU uptake in 9 month wild-type forebrain ventricles. The sections show BrdU-positive Ecad ${ }^{\mathrm{Wt} / \mathrm{Wt}}$ neural precursors (arrow) after $1 \mathrm{~h} \mathrm{BrdU}$ exposure in vivo. i shows brightfield. BrdU is green (ii, iii) and nuclei are counterstained in red by a pan-histone antibody (iii). C, BrdU uptake in 9 month E-Cadherin conditional knock-out forebrain ventricles. Sections show BrdU Ecad ${ }^{\Delta / \Delta}$-positive neural precursors (arrows) after $1 \mathrm{~h}$ BrdU exposure in vivo.i shows brightfield. BrdU is green (ii, iii) and nuclei are red (iii). Note the increase in Ecad ${ }^{\Delta / \Delta}$ cells entering S-phase during short-term BrdU administration. D, BrdU uptake is increased but BrdU retention is decreased in 9 month $\mathrm{E}$-Cadherin conditional knock-out forebrain ventricular subependyma. Left, The graph shows increase in BrdU ${ }^{+}$progenitors in $\mathrm{Ecad}^{\Delta / \Delta}$ mice $(n=4)$ compared with their Ecad ${ }^{\text {Wt/Wt }}$ littermate controls $(n=5)$ at 9 months of age. The asterisk indicates that the difference in BrdU ${ }^{+}$nuclei after $1 \mathrm{~h} \mathrm{BrdU}$ exposure is significant $(t=6.013 ; \mathrm{df}=88 ; p<0.05)$. Right, Same graph shows decrease in 9-month-old BrdU ${ }^{+}$retaining progenitors, 1 month after BrdU administration, in Ecad ${ }^{\Delta / \Delta}$ mice $(n=5)$ compared with their Ecad ${ }^{\mathrm{Wt} / \mathrm{Wt}}$ littermate controls $(n=5)$. The asterisk indicates this reduction is significant $(t=3.899$; $\mathrm{df}=118 ; p<0.05)$ in contrast to that observed in 2 month animals. $E$, GFAP is present in both wild-type and conditional knock-out forebrain ventricles. Confocal micrographs show GFAP positivity in both Ecad ${ }^{\mathrm{Wt} / \mathrm{Wt}}\left(\boldsymbol{i}\right.$, iii) as well as Ecad ${ }^{\Delta / \Delta}$ (ii, iv) SVZ cells. E-Cadherin is green, GFAP is blue, and nuclei are counterstained red. The boxed area in $\boldsymbol{i}$ is shown magnified in iii, and ii i in iv. $\boldsymbol{F}$, E-Cadherin conditional knock-out forebrain shows normal cell demographics. The graph shows numbers of GFAP, PSA-NCam, and Nestin-positive cells present in the 9-month-old forebrain of Ecad ${ }^{\text {Wt/Wt }}$ and $\mathrm{Ecad}^{\Delta / \Delta}$ animals. No significant differences are noted in the presence of any of these cell types ( $n=3$ animals of each genotype sampled). G, E-Cadherin loss leads to reduction in GFAP and Nestin BrdU-retaining cells in 9-month-old animals. The graph shows numbers of BrdU-retaining cells that colabel for GFAP, PSA-NCam, or Nestin. The asterisks show that there are significant differences between Ecad ${ }^{\mathrm{Wt} / \mathrm{Wt}}$ and Ecad ${ }^{\Delta / \Delta}$ GFAP-expressing cells $(t=5.758 ; \mathrm{df}=4 ; p<0.05)$ as well as Nestin-expressing cells $(t=4.341 ; \mathrm{df}=4 ; p<0.05)$. These results contrast with the generally equivalent labeling of GFAP and Nestin in the aged forebrain and suggest the decreases in these numbers are specific to the BrdU-retaining cell population. Error bars indicate SEM.

subependymal zone. The decrease in NSC numbers in aged animals may reflect a decrease in self-renewal of NSCs, or a senescence or increased cell death in this population.

Nine-month-old E-Cadherin conditional knock-outs were further examined to assess the demography of neural cells in the forebrain germinal zone. Ecad ${ }^{\mathrm{Wt} / \mathrm{Wt}}$ and $\mathrm{Ecad}^{\Delta / \Delta}$ mice were found to contain cells expressing GFAP, Nestin, PSA-NCam (Fig. $2 E, F$ ), as well as Sox 2 and CD-133 (data not shown) in approximately equivalent proportions between genotypes. However, when assessing specifically BrdU-retaining cells, Ecad ${ }^{\Delta / \Delta}$ were found to have less GFAP- and Nestin-expressing cells, whereas cells expressing PSA-NCam were in equivalent proportions be- 
tween genotypes (Fig. 2G). Because NSCs are thought to express GFAP (Imura et al., 2003; Morshead et al., 2003), this suggested that the population of NSCs was still present, although reduced, in the $\operatorname{Ecad}^{\Delta / \Delta}$ animals.

To further characterize the differences between wild-type and conditional E-Cadherin knock-out mice, electron microscopy was performed. No obvious differences were noted in the organization of the NSC niche on loss of E-Cadherin. In particular, it was evident that the NSCs (type B cells) were still present and possessed adherent junctions contacting these to type A cells (Fig. 3A). As well, it was observed that B cells contacted ependymal cells by adherens junctions as well (Fig. $3 B$ ). Because $\mathrm{N}$-Cadherin is abundant in the brain, it is possible that the absence of E-Cadherin does not result in an obvious disorganization, or adhesion or cell polarity changes in type B cells in their niche.

We next quantified the different cells types via electron microscopy. The Ecad $^{\Delta / \Delta}$ mouse forebrain shows a significant decrease in the numbers of type B cells and an increase in the numbers of type $C$ cells (Fig. 3C). These results confirm that $\operatorname{Ecad}^{\Delta / \Delta}$ lose NSCs with aging, in accordance with the results observed in labelretaining cells. This reduction could be attributable to a decrease in self-renewal of NSCs, a senescence or increased cell death in this population. The increase in transitamplifying type $\mathrm{C}$ cell precursors is consistent with our results that show increases in short-term BrdU uptake. A higher number of proliferating type $C$ progenitor cells may account for the increased proliferation observed in the subependyma (Fig. $2 A, D)$. In contrast to these differences, the numbers of type A cells between Ecad ${ }^{\Delta / \Delta}$ and Ecad ${ }^{\mathrm{Wt} / \mathrm{Wt}}$ is equivalent (Fig. 3C). Unlike the type $\mathrm{B}$ or $\mathrm{C}$ cells, type A neuroblast progenitors are not affected by the loss of E-Cadherin.

Loss of E-Cadherin reduces NSC selfrenewal in vitro

Although a loss of long-term BrdUretaining cells in vivo is thought to reflect a reduction in NSC number, the in vitro clonal analysis of NSCs has been shown to provide another means to directly examine these cells. To resolve whether NSCs divided more or less frequently in the absence of E-Cadherin, we dissected and cultured neural cells obtained from 2-month-old ventricular subependyma in Ecad ${ }^{\mathrm{Wt} / \mathrm{Wt}}$ and $\mathrm{Ecad}^{\Delta / \Delta}$ and examined the growth of colonies using clonal conditions in vitro. It was predicted that, during culture in proliferation conditions, adult NSCs would be induced to divide more frequently than they do in vivo, and an

A.

B.

C.

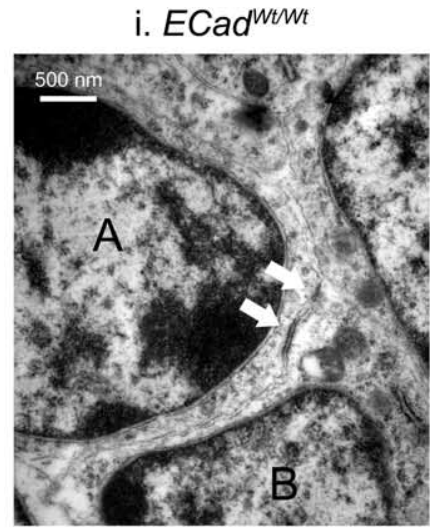

i. ECad ${ }^{W t w t}$
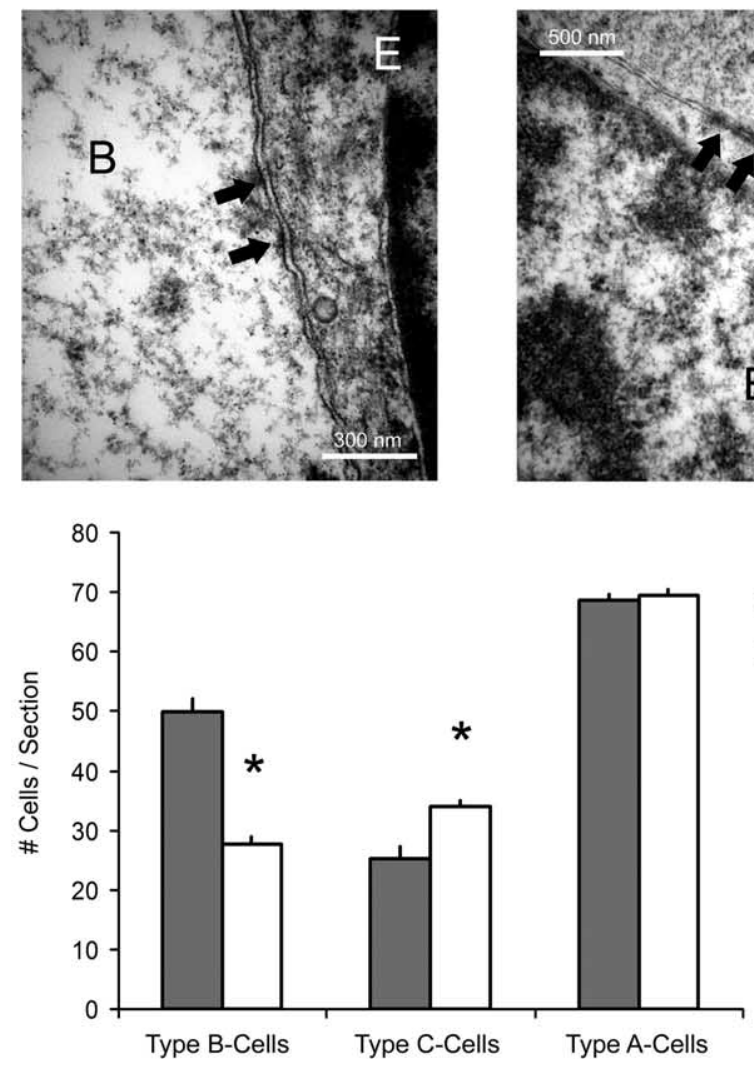

Figure 3. A, Adherent junctions between type $A$ and $B$ cells are present in the 9 month $E-C a d h e r i n$ conditional knock-out

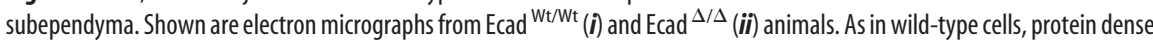
adherent junctions (arrows) were identified in conditional mutants, despite the loss of E-Cadherin in these cells. This may be attributable to the presence of $\mathrm{N}$-Cadherin, which is highly expressed in these cell types. " $\mathrm{A}$ " indicates type $\mathrm{A}$ cell, and " $\mathrm{B}$ " indicates type B cell. $B$, Ecad $^{\Delta / \Delta} B$ cells contact ependymal cells normally in the 9 month $E$-Cadherin conditional knock-out subependyma. Electron micrographs were examined in Ecad ${ }^{\mathrm{Wt} / \mathrm{Wt}}(\boldsymbol{i})$ and $\mathrm{Ecad}^{\Delta / \Delta}$ (ii) animals. It was found that Ecad ${ }^{\Delta / \Delta} \mathrm{B}$ cells contacted

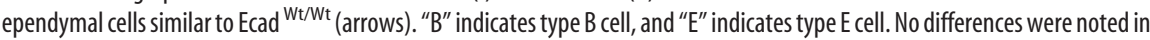
these structures between wild types and conditional mutants. C, E-Cadherin loss leads to reduction in B cells and increase in C cells in the 9 month E-Cadherin conditional knock-out subependyma. The graph shows numbers of cell types identified by electron microscopy in the subependymal zone. Although there are no differences in the number of type $A$ cells, Ecad ${ }^{\Delta / \Delta}$ mice show significant differences (asterisks) between B cells $(t=9.594 ; \mathrm{df}=38 ; p<0.05)$ and C cells $(t=6.584 ; \mathrm{df}=38 ; p<0.05)$. Counts are expressed per section; 20 sections were sampled from $n=3$ animals of each type, with at least six sections sampled per animal. Error bars indicate SEM.

eventual reduction in proliferation might occur (Kippin et al., 2005).

Initially, Ecad ${ }^{\Delta / \Delta}$ and Ecad ${ }^{\mathrm{Wt} / \mathrm{Wt}}$ animals produced similar numbers of clonal colonies (Fig. $4 A$ ). However, on two serial passages, Ecad ${ }^{\Delta / \Delta}$ produced fewer colonies than Ecad ${ }^{\mathrm{Wt} / \mathrm{Wt}}$, and 
A.

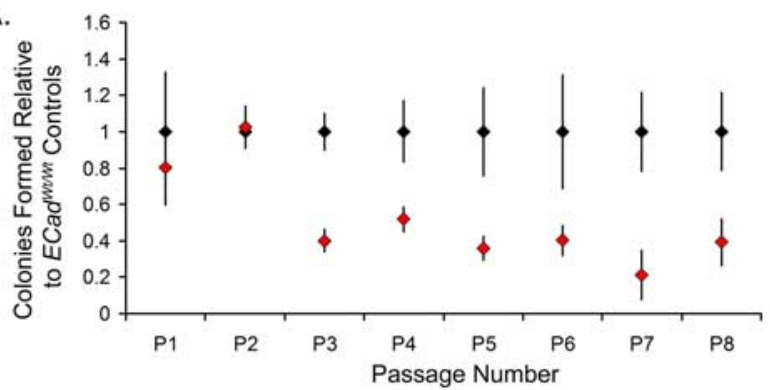

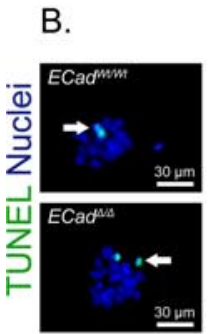

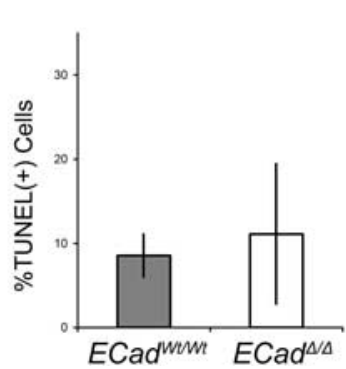

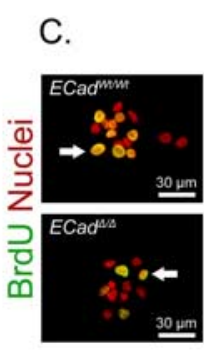

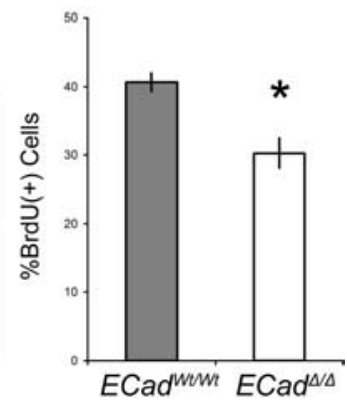

Figure 4. A, NSC colony formation is reduced in E-Cadherin conditional knock-outs. The graph shows the inability of Ecad ${ }^{\Delta / \Delta}$ NSCs to maintain over long-term passage, in contrast to $\mathrm{Ecad}{ }^{\mathrm{Wt} / \mathrm{Wt}}$ littermate controls. Clonal NSC colonies were averaged arising from every 5000 cells plated on dissection, or 2500 cells plated after passage. The averages from Ecad ${ }^{\Delta / \Delta}$ were normalized to the $\mathrm{Ecad}^{\mathrm{Wt} / \mathrm{Wt}}$ controls. Colonies of Ecad ${ }^{\Delta / \Delta}$ begin to show a deficit in number at passage 3 after dissection (P3) and maintain this deficit thereafter. The remaining colonies were passaged exactly as wild types; both were replated in 24-well plates. Differences between $E \mathrm{Ead}^{\mathrm{Wt} / \mathrm{Wt}}$ and $\mathrm{Ecad}{ }^{\Delta / \Delta}$ are significant at passages 3 onward, and the interaction between genotype and passage is significant $\left(F_{(15,109)}=1.946 ; p<0.05\right)$. Primary time point is an average of cells dissected from $n=10\left(\operatorname{Ecad}^{\Delta / \Delta}\right)$ and $n=11$ $\left(\mathrm{Ecad}^{\mathrm{Wt} / \mathrm{Wt}}\right)$ animals; the remaining time points contain $n=7$ mice per passage Ecad ${ }^{\Delta / \Delta}$ and $n=4-6$ mice per passage $\mathrm{Ecad}^{\mathrm{Wt} / \mathrm{Wt}} \cdot{ }^{B}$, Cell death is equivalent between wild-type and $\mathrm{E}$-Cadherin conditional knock-out colonies. Images show merge of $3 \mathrm{~d} \mathrm{Ecad}{ }^{\Delta / \Delta}$ and Ecad ${ }^{W t / W t}$ colonies at passage 3, the time point at which differences in colony number arise between these groups. TUNEL assay (arrow) reveals cell nuclei undergoing apoptosis (green); nuclei are counterstained by DAPI (blue). The graph shows that there are no significant differences $(p>0.05)$ between the proportion of TUNEL ${ }^{+}$cells per colony $(n=3$ animals per group). C, Proliferation is decreased in E-Cadherin conditional knock-out colonies at passage 3. Images show merge of $3 \mathrm{~d}$ $\mathrm{Ecad}^{\Delta / \Delta}$ and Ecad ${ }^{\mathrm{Wt} / \mathrm{Wt}}$ colonies at passage 3 , the time point at which differences in colony number arise between these groups. BrdU uptake (arrow) reveals nuclei that have entered S-phase (yellow in merged image). Nuclei are counterstained using panhistone (red). The graph shows that there are significant differences (asterisk) between the proportion of $\mathrm{BrdU}^{+}$cells per colony $(t=4.043 ; \mathrm{df}=4 ; p<0.05 ; n=3$ animals per group). Error bars indicate SEM.

this decrease was maintained thereafter (Fig. 4A). Heterozygous $\mathrm{Ecad}^{\Delta / \mathrm{Wt}}$ NSCs produced equal numbers of colonies to Ecad $^{\text {Wt/Wt }}$ NSCs (data not shown). Both conditional knock-outs and heterozygous neurospheres were of similar size as wild types, even after a decrease in the number of neurospheres became apparent. The step function loss in clonal neurosphere number suggests a halving, followed by maintenance of lower numbers, of multipotent NSCs in these in vitro conditions.

To test whether neurospheres derived from $\mathrm{Ecad}^{\Delta / \Delta}$ animals were restricted progenitors or multipotent NSCs, we examined $\mathrm{Ecad}^{\Delta / \Delta}$ versus Ecad ${ }^{\mathrm{Wt} / \mathrm{Wt}}$ colonies arising from newly dissected cells under differentiation conditions to ascertain whether differences existed in their output of neural progeny. There were no differences among these groups tested, with both wild-type (colonies sampled from $n=6$ animals) and mutant colonies (sampled from $n=6$ animals) giving rise to equivalent numbers of neurons, as assessed by the use of $\beta$-III-tubulin, and astrocytes, as assessed by the use of GFAP (data not shown). Together with the long-term passaging results above, these data suggest that the neurospheres dissected from $\mathrm{Ecad}^{\Delta / \Delta}$ animals derive from NSCs and not progenitors.

Under in vitro conditions, NSCs are the cells within colonies with the ability to subclone. The number of subclone-competent cells at $7 \mathrm{~d}$ after passage is $1.3 \pm 0.5 \%$ of total cells. However, the proportion of NSCs is significantly higher at 2-3 d after passaging, when $3.9 \pm$
$0.8 \%$ of the total cell population can subclone $(t=19.26$; $\mathrm{df}=101 ; p<0.05)$. This means 2-3 d after passage, single NSCs are present at higher frequencies than they are at day 7 . We took advantage of this to test the effects on E-Cadherin in NSCs. It is possible that the reduction in neurosphere number was an outcome of increased cell death in the $\operatorname{Ecad}^{\Delta / \Delta}$ cells because E-Cadherin has been shown to mediate cell survival in other tissues (Boussadia et al., 2002; Tinkle et al., 2004). Colonies were examined at the passage 3 time point when a significant decrease between E-Cadherin wild-type and mutant cultures was first observed. No differences in cell death were observed between $\operatorname{Ecad}^{\Delta / \Delta}$ and Ecad ${ }^{\mathrm{Wt} / \mathrm{Wt}}$ colonies at $3 \mathrm{~d}$ culture when these were examined by TUNEL (Fig. 4B).

Cell division rate might also be a means through which clonal NSC colony number decreases in passaged NSCs. Hence similar third-passage colonies were pulsed for $4 \mathrm{~h}$ in vitro with BrdU and subsequently examined. A significant decrease in overall cell proliferation was observed in $\operatorname{Ecad}^{\Delta / \Delta}$. derived clones (Fig. 4C). Interestingly, when such colonies were examined for BrdU uptake at the passage 2 time point, before a reduction in clone number was seen, there were no significant differences between $\operatorname{Ecad}^{\Delta / \Delta}$ and Ecad ${ }^{\mathrm{Wt} / \mathrm{Wt}}$ groups (data not shown). These data suggest that NSC and neural progenitor division rate and NSC number are reduced over extended periods of time in vitro.

Together, these data forecast a premature depletion of the NSC pool in older $\operatorname{Ecad}^{\Delta / \Delta}$ mice. We reexamined the production of neural stem cells colonies to verify whether such a decrease was apparent over time. Dissections were performed on older 9 month $\operatorname{Ecad}^{\Delta / \Delta}$ mice to test whether the number of NSCs is lowered at later time points. In line with this prediction, primary Ecad ${ }^{\Delta / \Delta}$ colony number was significantly decreased compared with wild types in aged animals. In three separate assays, $\operatorname{Ecad}^{\Delta / \Delta}$ mice $(n=10)$ formed $63.0 \pm$ $7.0 \%$ neurosphere colonies relative to Ecad ${ }^{\mathrm{Wt} / \mathrm{Wt}}$ littermate controls $(n=11)$ at 9 months of age $(t=2.867$; $\mathrm{df}=19 ; p<0.05)$. The difference in primary sphere numbers in such old animals contrasted with those obtained from 2-month-old animals, when Ecad $^{\Delta / \Delta}$ and Ecad ${ }^{\mathrm{Wt} / \mathrm{Wt}}$ contained equal proportions of colonyforming NSCs.

Our results suggest that the number of NSCs is initially normal in young Ecad ${ }^{\Delta / \Delta}$ animals but is prematurely exhausted over time. Either an impaired NSC self-renewal in Ecad ${ }^{\Delta / \Delta}$ mice only becomes evident over many NSC divisions, or the loss of E-Cadherin attachment of NSCs in the niche leads to their eventual differentiation. NSC losses are then manifested by decreases in colony formation in vitro and in BrdU-retaining cells in vivo.

\section{Disruption of E-Cadherin adhesion reduces NSC self-renewal} in vitro

It is possible that compensatory mechanisms, such as $\mathrm{N}$-Cadherin upregulation, occur in conditional E-Cadherin 
knock-outs and mask effects mediated by E-Cadherin. The functional role of E-Cadherin in vitro was directly investigated in wild-type mice, using adhesion-blocking antibodies that specifically target cadherin extracellular adhesive domains. Homophilic E-Cadherin binding between adjacent cells has been shown to elicit signal transduction simply by engaging the extracellular domains of cadherins (Liu et al., 2006; Perrais et al., 2007). Additionally, as with the Ecad ${ }^{\Delta / \Delta}$ mutants, blocking of Cadherin binding might also decrease cell to cell contact in wild-type NSCs (Bendel-Stenzel et al., 2000).

Adult CD1 wild-type cells dissected from the adult forebrain ventricular subependyma were grown, passaged, and raised in the presence of such antibodies for $7 \mathrm{~d}$. Clonal adult neurosphere number decreased in the presence of E-Cadherin and $\mathrm{N}$-Cadherin antibodies in a dosage-dependent manner in contrast to P-Cadherin antibody, which had no effect on clonal colony formation (Fig. 5A). The colonies observed in these adhesion-blocking conditions appeared equal in size as their untreated counterparts (data not shown). Notably, both E-Cadherin blocking antibodies demonstrated negative effects on colony number at high concentrations. This suggests that specifically blocking either E-Cadherin or N-Cadherin adhesion itself in neurosphere cells leads to a decrease in NSC self-renewal.

NSC cultures were grown in the presence of cadherin blocking antibodies at $1.0 \mu \mathrm{g} / \mathrm{ml}$, a concentration at which a reduction in colony number is observed using the ECCD1 $\alpha$-E-Cadherin antibody (Fig. 5A). Although a reduction in clonal colony number was observed for both ECCD 1 and $\alpha$-N-Cadherin, the colonies successfully raised in the presence of these antibodies appeared normal. These colonies then were passaged a second time to see whether any effects of $\alpha$-E-Cad or $\alpha$-N-Cadherin were apparent in the cells in these colonies. In the absence of E-Cadherin antibody, the number of secondary colonies arising from primary ones grown in E-Cadherin and N-Cadherin blocking antibodies were also reduced (Fig. 5B) showing that E- and N-Cadherin engagement also reduced NSC self-renewal in the primary colonies. However, by the third passage, colonies derived from E-Cadherin-exposed cells produced similar numbers of NSC progeny (Fig. 5C) as ones grown from cells never exposed to antibody block. These data show that the decrease in NSC number under conditions of lessened E- and N-Cadherin adhesion is reversible in wild-type cells.

Neural cells begin to divide after 1-2 d on passage under clonal proliferation conditions (P. Karpowicz and D. van der Kooy, unpublished observations). From each $7 \mathrm{~d}$ colony, a small subset of the progeny [of 3500 total cells (Karpowicz et al., 2005)] have the competence to subclone. We applied Cadherin antibodies to colonies at day 3 , a time point at which $<10$ cells are present in each clonal colony. Intriguingly, no reduction in colony number is observed when antibodies are applied at this point (Fig. 5D). It is possible that these antibodies take effect on the niche when NSCs are present at higher frequency in the first few days after plating, than when colonies are fully formed.

Cell death was next examined in cells initially exposed to antibody to see whether this might explain a reduction in NSC number before cells begin to divide. Trypan blue exclusion showed that, in the first $24 \mathrm{~h}$ that single cells were exposed to antibody, no differences in cell death were apparent between cells (Fig. 5E). These data show that the effects of adhesion blocking antibodies are not attributable to toxicity before cells divide.

Disruption of E-Cadherin adhesion reduces NSC number during the first few divisions of these cells in vitro. Because these effects also take place on primary clonal colonies as well as on passaged colonies, these data are consistent with the notion that a NSC divides to produce niche support cells. Such cells maintain the NSC in an undifferentiated state, but when this adhesion is blocked a deficiency in NSC number ensues.

The effects of blocking E-Cadherin adhesion on differentiation were next assayed. Although we previously noted no effects on the differentiation between $\mathrm{Ecad}^{\Delta / \Delta}$ and Ecad ${ }^{\mathrm{Wt} / \mathrm{Wt}} \mathrm{NSCs}$, the possibility that E-Cadherin adhesion would affect NSC differentiation was examined in wild-type cells that carry a functional E-Cadherin gene. First, colonies raised in the presence of antibody and differentiated in the presence of antibody were examined. In these conditions, curious phenotypes were observed in neuronal and glial cells exposed to E-Cadherin blocking antibodies, in particular ECCD-1 (Fig. 5Fi). In contrast, P-Cadherin blocking antibodies (Fig. 5Fii) demonstrated no altered phenotype. Not only did E-Cadherin antibody abolish neuronal production (Fig. 5Gi), but in these conditions $\mathrm{GFAP}^{+}$astrocytes were reduced in number (Fig. 5Gii) and the diameter of the processes of those that remained was decreased, when either E- and $\mathrm{N}$-Cadherin were blocked. The most significant effects were observed with the ECCD- 1 and $\alpha$-N-Cadherin antibodies. The normal differentiation noted in NSCs grown in ECCD-2 rather than ECCD-1 is likely a result of the concentrations of this antibody, which is only observed to produce proliferation deficits at higher concentrations than $1.0 \mu \mathrm{g} / \mathrm{ml}$ (Fig. 5A).

Second, colonies grown in normal (nonantibody) proliferation conditions, but differentiated in the presence of E-, N-, or P-Cadherin blocking antibodies, were assayed for alterations in their output of differentiated progeny. We found no differences in either $\beta$-III-tubulin ${ }^{+}$neurons or $\mathrm{GFAP}^{+}$astrocytes in NSC colonies differentiated in any of the blocking antibodies (data not shown). Finally, colonies raised in the presence of cadherin function blocking antibodies, but differentiated in the absence of the antibodies, were examined. Again, there were no differences in the proportion GFAP ${ }^{+}$ cells; however, neuron production was reduced when $\mathrm{N}$-Cadherin or E-Cadherin antibody is present during proliferation but not differentiation (data not shown).

These data show that blocking of endogenous E-Cadherin decreases neuronal differentiation in vitro. Because these effects do not occur during differentiation conditions, E-Cadherin dependency is not a feature of neurons themselves but, rather, the proliferation of a neuronal progenitor when E-Cadherin adhesion is blocked during colony formation. This results in a loss of neuronal cells produced from the neuronal progenitors. As well, a reduction in E- and N-Cadherin adherence reduces astrocyte production. However, this effect only takes place if both proliferation and differentiation are undertaken in the presence of blocking antibodies, suggesting that cellular adhesion may be critical during the transition of an undifferentiated precursor into a differentiated astrocyte. Such an effect is not seen in the Ecad ${ }^{\Delta / \Delta} \mathrm{mu}^{-}$ tant, suggesting that a compensatory mechanism overcomes this deficiency in the mutant.

Together, these experiments indicate that inhibiting E-Cadherin adhesion reduces NSC number. Such phenomena only take place during the first divisions of NSC and/or neural progenitors in vitro, are reversible, and do not take effect through the death of NSCs. E-Cadherin also appears to affect the differentiation of astrocytic cells, because these transition from an undifferentiated to a differentiated state. 


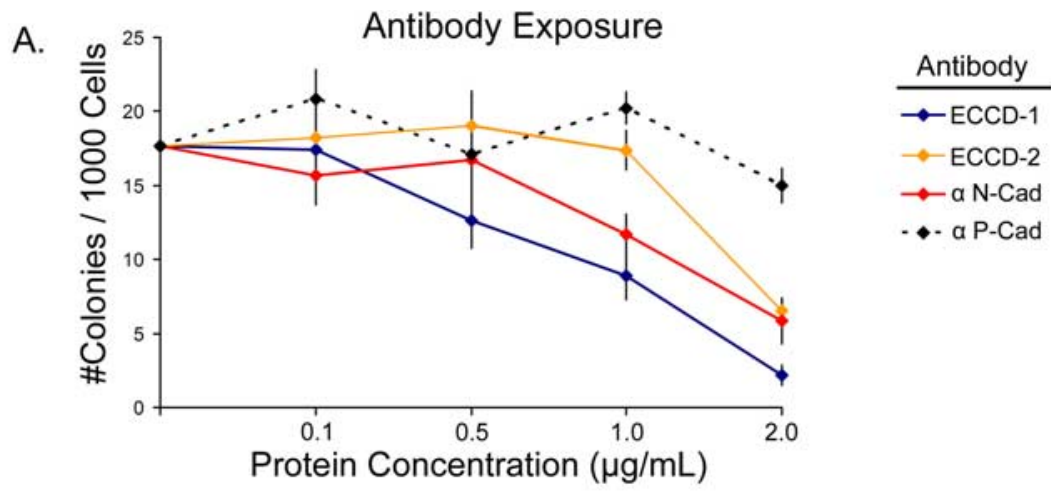

B.

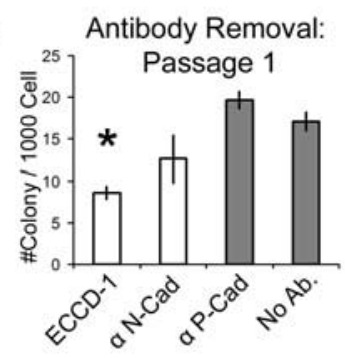

C.

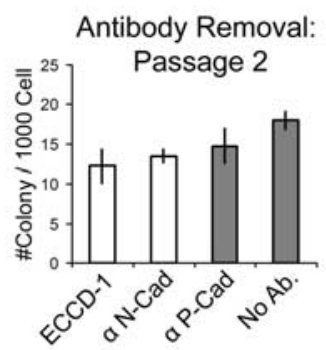

D.

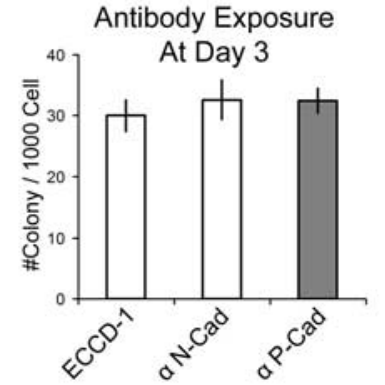

E. $24 \mathrm{~h}$. Antibody Exposure

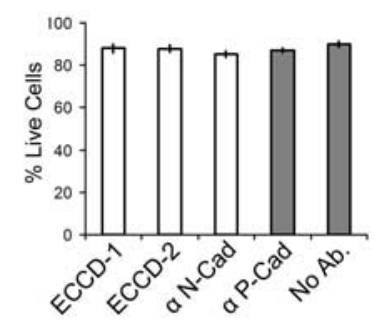

F.

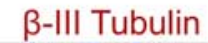

i. ECCD-1
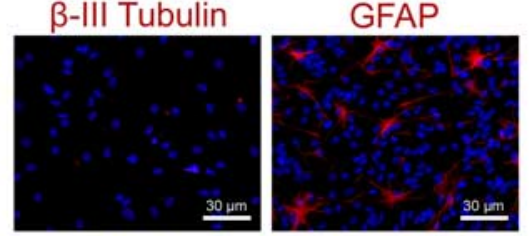

ii. a P-Cad

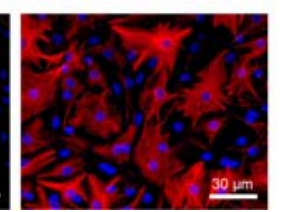

G.
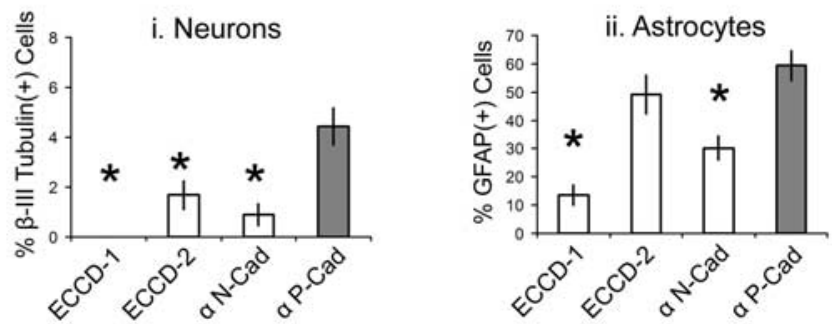

Figure 5. $\quad \boldsymbol{A}, \mathrm{E}$-Cadherin antibodies reduce NSC colony formation in a dose-dependent manner. The graph shows decrease in number of primary colonies as adhesion blocking $\alpha$-Cadherin antibody concentration increases. Colony formation in $\alpha$-P-Cadherin antibody does not vary at any concentration $(p>0.05)$. The interaction between antibody and dosage is significant $\left(F_{(153,57)}\right.$ $=15.75 ; p<0.05)$. Multiple-comparison tests show that, at $1.0 \mu \mathrm{g} / \mathrm{ml}$ concentration, ECCD-1 and $\alpha$-N-Cadherin antibody induce a significant decrease in the number of colonies relative to $\alpha$-P-Cadherin. At $2.0 \mu \mathrm{g} / \mathrm{ml}$ concentration, the numbers of colonies with all three antibodies (ECCD-1, ECCD-2, and $\alpha$-N-Cadherin) are significantly lower than $\alpha$-P-Cadherin. B, Secondary NSC colony formation is only affected by E-Cadherin adhesion block. Secondary colonies were grown in the absence of antibody. The graph shows a decrease in colony number (asterisk) observed in colonies subcloned from cells exposed to $1.0 \mu \mathrm{g} / \mathrm{ml} \mathrm{ECCD}-1$ antibody but not $\alpha$-N-Cadherin or $\alpha$-P-Cadherin during primary colony formation. An ANOVA test shows main effect of antibody $\left(F_{(153,84)}\right.$ $=17.14 ; p<0.05$ ), and multiple-comparison tests show that only ECCD-1 is different from control cells never exposed to antibody. C, Tertiary NSC colony formation is normal. The graph shows recovery in colony formation observed in tertiary spheres grown for two passages, in the absence of antibody, after exposure to $1.0 \mu \mathrm{g} / \mathrm{ml} \mathrm{during} \mathrm{primary} \mathrm{colony} \mathrm{formation.} \mathrm{Cells} \mathrm{never} \mathrm{exposed} \mathrm{to}$ antibody produce similar numbers of spheres as any of the antibody-exposed groups. An ANOVA shows there are no significant differences between any of the groups tested $\left(F_{(153,72)}=2.16 ; p>\right.$ 0.05). D. Antibody exposure at day 3 of colony formation does not affect colony number. The graph shows that, unlike the decreases observed when plating cells directly into $\alpha$-Cadherin antibodies (Fig. $3 A, B)$, there are no differences among antibodies when the antibodies are applied at $1.0 \mu \mathrm{g} / \mathrm{ml}$ at day 3 in vitro $\left(F_{(152,14)}=0.30 ; p>0.05\right)$. These results suggest colony decreases are attributable to antibody effects during the first $3 \mathrm{~d}$. $\boldsymbol{E}$, Adhesion block does not induce cell toxicity. The graph shows that exposure to antibodies at $1.0 \mu \mathrm{g} / \mathrm{ml}$ does not influence cell death. In no case did antibodies increase cell death over controls plated in the absence of antibody $\left(F_{(154,24)}=1.33 ; p>0.05\right) . F$, $\alpha$-E-Cadherin affects the differentiated progeny of NSCs. Images show colonies of NSCs grown and differentiated in the presence of ECCD-1 (i) or $\alpha$-P-Cadherin (ii) antibodies. Proteins of interest are shown in red; nuclei are counterstained in blue (DAPI). Note the obvious altered morphology and number of neurons ( $\beta$-III Tubulin ${ }^{+}$) and astrocytes (GFAP ${ }^{+}$) types grown in ECCD-1 as opposed to $\alpha$-P-Cadherin control antibody. $G$, Neuron and astrocyte number is reduced under conditions of E-Cadherin and N-Cadherin adhesion block. The graphs show reduction in neuronal production ( $n=4$ colonies sampled; main effect of antibody, $\left.F_{(153,13)}=9.831, p<0.05\right)$ (i) and astrocyte production ( $n=4$ colonies sampled; main effect of antibody, $F_{(153,15)}=15.89, p<0.05$ ) (ii) by NSC colonies. Colonies were both grown and differentiated in presence of antibody. The asterisks indicate groups that are significantly different from $\alpha$-P-Cadherin control in multiple-comparison tests. Error bars indicate SEM.

\section{Increased E-Cadherin adhesion increases NSC number in vitro}

We sought to determine what effect an overabundance of E-Cadherin would have on NSCs in vitro. Adult CD1 NSCs were infected with retroviruses carrying human E-Cadherin, $\mathrm{N}$-Cadherin, or an $\mathrm{E}$-Cadherin sequence with the $\beta$-Catenin binding domain removed ( $\Delta \mathrm{E}$-Cadherin). This last construct would allow the specific effects of only the extracellular E-Cadherin adhesive domain to be tested with no intracellular domain, which is known to affect Wnt signaling by binding $\beta$-Catenin (Gottardi et al., 2001).

One week after infection, E-Cadherin as well as $\Delta$ E-Cadherin- 

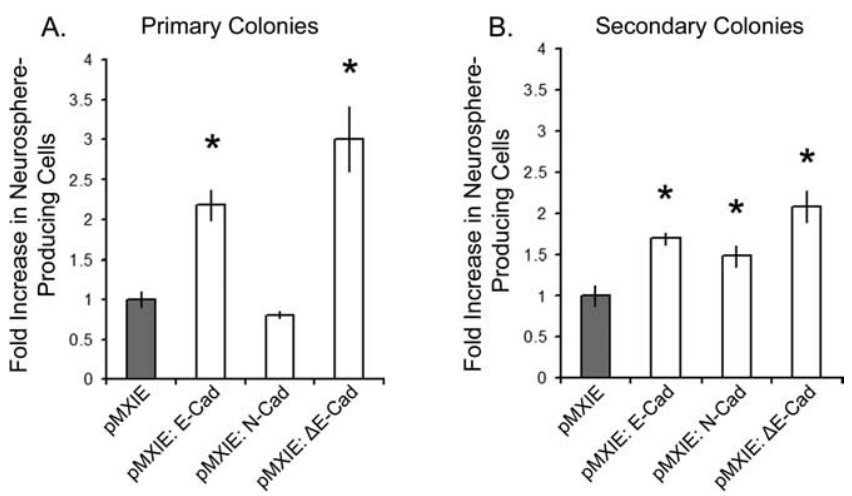

Figure 6. A, E-Cadherin increases primary clonal NSC colony formation. The graph shows an increase in neurosphere production when NSCs are induced to overexpress E-Cadherin. ANOVA indicates main effect of vector $\left(F_{(153,207)}=29.93 ; p<0.05\right)$. The asterisks indicate pMXIE:ECad and pMXIE: $\Delta$ E-Cad significantly increase colony number over control pMXIE. B, E-Cadherin and N-Cadherin increase secondary clonal NSC colony formation. Clones from $\boldsymbol{A}$ were passaged to assess overexpression effect on secondary colony formation. The graph shows increase in number of colonies on passage, after $\mathrm{E}$ - or $\mathrm{N}$-Cadherin overexpression. ANOVA test shows main effect of vector $\left(F_{(153,177)}=31.03 ; p<0.05\right)$. The asterisks indicate pMXIE:E-Cad, pMXIE:NCad, and pMXIE: $\Delta \mathrm{E}$-Cad are all significantly higher than control pMXIE. Error bars indicate SEM.

overexpressing cells produced increased numbers of neurosphere clones compared with cells expressing a control retrovirus or those expressing the N-Cadherin transgene (Fig. 6A). Because there is a possibility of transgene suppression in these cells, we confirmed that, at this time point, $69.2 \pm 5.1 \%$ of neurosphere cells were still positive for a GFP reporter that indicated successful transduction, and, of these, $78.1 \pm 2.3 \%$ reacted positively for E-Cadherin antibodies as assessed by flow cytometry. Although not all cells were positive at this time point, the increased incidence of Cadherin expression was sufficient to alter the numbers of clones arising from E-Cadherin but not N-Cadherin retrovirus-treated cells (Fig. 6A). This suggested increased E-Cadherin adhesion increases the number of NSCs capable of forming neurosphere colonies, perhaps by improving NSC to niche-cell contact during the first few divisions of NSCs. Moreover, these increases in colony number were not a general increase in proliferation, because colony size was not altered in the E-Cadherin or $\Delta \mathrm{E}$-Cadherin-overexpressing NSCs (data not shown).

We passaged the clones arising from this experiment to see whether the overexpression of E-Cadherin would continue to exert itself over time. Similar to our initial results, E-Cadherin and $\Delta \mathrm{E}$-Cadherin increases led to more secondary colonies than control retrovirus, although it was noted that N-Cadherin overexpression (which did not increase primary clone number) now led to greater numbers of secondary clones as well (Fig. 6B). Single $\mathrm{GFP}^{+}$colonies (indicating successful transgene induction) from either E-Cadherin, $\mathrm{N}$-Cadherin, or $\Delta \mathrm{E}$-Cadherin were passaged to confirm that the overexpression of cadherins in these founder cells leads to increased numbers of colonies. E-Cadherin, $\mathrm{N}$-Cadherin, and $\Delta \mathrm{E}$-Cadherin-overexpressing NSC colonies produced greater numbers than control colonies (data not shown). These results suggest that E-Cadherin and N-Cadherin adhesion support greater NSC numbers. In these passaged cells, either increased adhesiveness improves cellular contact during the initial divisions (as it might with primary neurospheres) or NSCs possess a cellular memory caused by specific Cadherinmediated adhesion present during primary colony formation.

Importantly, the increase in NSC colony number via Cadherin overexpression shows that, if anything, Cadherins cause increased rather than decreased symmetric NSC division. This argues against the possibility that, under conditions in which
E-Cadherin is abolished in the $\mathrm{Ecad}^{\Delta / \Delta}$ animals, symmetric NSC division was increased, which spent the NSC population prematurely. Thus, these results more likely suggest that, by increasing the closeness of colony cells, NSCs are themselves increased, either through more symmetric divisions or by the maintenance of NSCs in an undifferentiated state.

\section{Discussion}

The adhesion protein E-Cadherin regulates NSC numbers in the subependyma of the adult forebrain ventricles. We envision three possible explanations that account for the regulation of NSC numbers by E-Cadherin: (1) NSCs divide either more or less frequently depending on the level of this protein, (2) NSCs survive more or less depending on the level of this protein, and (3) NSCs are maintained in an undifferentiated state by a E-Cadherin-mediated niche that alters their asymmetric versus symmetric mode of division. How does E-Cadherin perturbation best fit these processes?

It is unlikely E-Cadherin alters the rate of NSC divisions, although it does seem to increase cell division in neural progenitors in vivo. Older Ecad ${ }^{\Delta / \Delta}$ animals have lower numbers of NSCs than Ecad $^{\mathrm{Wt} / \mathrm{Wt}}$, which might suggest exhaustion of the NSC pool because of an increase in NSC division rate early on. However, if this was the case, younger Ecad ${ }^{\Delta / \Delta}$ brains should contain more NSCs than $\mathrm{Ecad}^{\mathrm{Wt} / \mathrm{Wt}}$. This does not seem to be the trend as 2 month animals of both genotypes have equal numbers of NSCs. Moreover, the application of function-blocking antibody does not increase symmetric NSC divisions (no increase in secondary colony formation in the absence of antibody) and NSCs recover after the removal of antibody. Therefore, E-Cadherin does not regulate the rate of NSC division and we suggest that the effects seen are not attributable to premature senescence of NSCs.

It is unlikely E-Cadherin affects the survival of NSCs. No differences in the proportion of TUNEL-labeled cells are seen in Ecad $^{\Delta / \Delta}$ versus Ecad ${ }^{\mathrm{Wt} / \mathrm{Wt}}$ in vitro, although these produce different numbers of colonies. The perturbation of E-Cadherin adhesion by antibody also reduces NSC number on secondary passage in vitro. However, no decrease is evident in NSC numbers if antibody is applied at day 3 of culture and no increase in cell death is observed on exposure of antibody. Thus, we exclude reduced NSC survival alteration to explain these results.

Perhaps the simplest interpretation of this study is that E-Cadherin regulates the differentiation of NSCs through a niche-cell mechanism. If this is true, one would predict symmetric divisions to be increased by E-Cadherin, because protein overexpression increases NSC number in the niche and antibody block or genomic deletion decreases NSC number. E-Cadherin would thus regulate NSC differentiation status. E-Cadherin-positive NSCs need close contact with E-Cadherin-expressing support cells that regulate NSC number by allowing these to divide asymmetrically to self-renew and to resist an intrinsic differentiation program. The presence of this adhesion may indirectly affect other juxtacrine signaling processes between NSCs and adjacent cells. Without this association, the NSC pool is lower in animals that do not contain neural E-Cadherin and this decrease becomes apparent over time. The stepwise loss of 2-month-old Ecad ${ }^{\Delta / \Delta}$ NSCs on passage suggests a halving of a juxtacrine self-renewing signal such as Notch, which maintains NSCs (Hitoshi et al., 2002). The reduction in NSC numbers on exposure of primary colonies to antibody block and the subsequent reduction in secondary colony number from colonies raised in antibody block similarly support this explanation. If this third interpretation is indeed correct, our in vitro results suggest NSCs are the founders 
of niche cells (because E-Cadherin effects are seen in clonal NSC colonies in this system). The identity of these support cells is unclear; these may be any neural cell types including NSCs themselves. This idea that stem cells form their own niches in culture is not without precedence. It has for instance been observed that embryonic stem cells can form their own niches, cell autonomously, by producing differentiated progeny that support the undifferentiated founder cells themselves (Bendall et al., 2007).

E-Cadherin regulation of NSC division symmetry might act directly through a parallel signaling pathway that is affected by adhesion. In conditions of increased Cadherin presence, the number of SCs contacting support cells would affect the signals SCs received. Contacting cells might thus determine the functional symmetry of NSC division by physical closeness; those NSCs that do not contact support cells in the niche would become progenitors (Lin, 1997). A related idea is that contact to a locus actually polarizes cells, allowing them to divide asymmetrically (Betschinger and Knoblich, 2004). Studies have demonstrated a polarization of cadherins in precursors in a variety of systems (Song et al., 2002; Rasin et al., 2007). Indeed, it appears that the proteins Numb and Numblike function to polarize E-Cadherin in the processes connecting radial glia to the ventricles (Rasin et al., 2007). Our interpretations are consistent with these studies, although we did not find clear evidence of altered polarization when E-Cadherin is absent. However, we find that E-Cadherin promotes the NSC self-renewal symmetric mode of division, keeping the NSCs in an undifferentiated state.

In the fly gonad, Drosophila E-Cadherin has been shown to associate germline SCs with a group of cells that signal to the SCs and that, in part, define the SC niche (Song et al., 2002; Yamashita et al., 2003; Ohlstein et al., 2004). Germline SCs that cannot differentiate, upregulate cadherins that enable them to outcompete wild-type germline SCs for occupancy of the SC niche (Jin et al., 2008). Mouse E-Cadherin has been shown to induce Racl activity, which increases epithelial cell proliferation in vitro (Liu et al., 2006). E-Cadherin may also decrease cellular proliferation in a variety of cell lines by a $\beta$-Catenin-independent, noncanonical Wnt signaling pathway (Perrais et al., 2007). Moreover, E-Cadherin has been also found to have effects on the differentiation of murine germ cells (Okamura et al., 2003) and epithelia (Larue et al., 1996). These characteristics of maintenance and proliferation also support cadherins as regulators of SC behavior.

An alternative explanation to a niche-mediated self-renewal mechanism is that E-Cadherin directly signals to NSCs. Cadherins can participate in signaling processes through their sequestration of $\beta$-Catenin. Our results, which show that NSCs exposed to function-blocking antibodies differentiate differently than Ecad ${ }^{\Delta / \Delta}$ NSCs (Fig. $5 F, G$ ), seem to support a direct role of E-Cadherin rather than a niche-mediated role. That wild-type cells show altered differentiation under E-Cadherin block might argue for a direct signaling mechanism. However, our results also show that neurosphere number is halved in the presence of antibody (Fig. $5 A$ ), which is similar to the halving observed in Ecad $^{\Delta / \Delta}$ NSCs (Fig. $4 A$ ). These discrepancies are difficult to explain with any certainty. At this time, we are not able resolve between the direct role of E-Cadherin in NSC self-renewal versus a niche-mediated role.

The loss of colony number by E-Cadherin, but not $\mathrm{P}$-Cadherin antibody-exposed NSCs, suggests that E-Cadherin is specifically needed by adult NSCs. However, the differences observed between mutants and wild types, antibody-raised NSCs and controls, and Cadherin overexpressing NSCs and controls are no greater than twofold. In the $\mathrm{Ecad}^{\Delta / \Delta}$, this is perhaps attrib- utable to compensatory adhesion performed by N-Cadherin, which is known to be coexpressed with E-Cadherin in the ventricular zones (Rasin et al., 2007) and which we find in abundance in the $\mathrm{Ecad}^{\Delta / \Delta}$ forebrain germinal zones. In recent studies, both proteins were observed to polarize radial glia in this region, which means that the conditional ablation of one might be compensated for by the other. This accounts for our observation that $\mathrm{N}$-Cadherin retrovirus and blocking antibody phenocopy the same E-Cadherin perturbations, and it is possible conditional $\mathrm{N}$-Cadherin ablation in these regions would produce an equivalent phenotype as seen in the Ecad ${ }^{\Delta / \Delta}$. Differences in adhesion block by antibodies are most likely lessened because of insufficient concentrations of $\alpha$-E-Cadherin and $\alpha$-N-Cadherin, which produce more pronounced effects at higher doses.

Indeed, if E-Cadherin regulates NSC differentiation by a niche-type mechanism, this may account for the increase in BrdU uptake in progenitors after $1 \mathrm{~h}$ exposure in vivo. If E-Cadherin only affects NSCs, then these non-NSC neural progenitor phenotypes are a downstream outcome. Differentiating NSCs leave their relatively quiescent niche and enter a progenitor pool where proliferation is more rapid. This is then manifested as an increase in short-term BrdU uptake. At present, we cannot conclude whether E-Cadherin affects NSCs and non-NSCs differently. The specific ablation and overexpression in NSCs themselves would have to be performed to resolve this issue.

The regulation of SC number by support cells suggests a niche-dependent mechanism of sensing physiological change may exist in the brain. The upregulation of a particular Cadherin within precursors could increase SC binding to support cell groups, which increases the number of SCs through the dedifferentiation of progenitors into SCs (Yamashita et al., 2003; Brawley and Matunis, 2004; Kai and Spradling, 2004). Indeed, the observation that germline SCs with higher cadherin levels are more competitive in the niche of Drosophila (Jin et al., 2008) offers a tempting explanation for the increase in NSC colonies under conditions of cadherin overexpression (Fig. 6A). It is tempting to speculate that both NSCs and support cells have the ability to regulate NSC number, the former by intrinsically regulating its own expansion and the latter by limiting NSC expansion via regulation of E-Cadherin expression. In line with this reasoning, there is some evidence that suggests both Notch signalingdependent niche cells and Dpp signaling-dependent SCs participate in bidirectional signaling processes that simultaneously regulate the SC and niche cell pool (Ward et al., 2006; Song et al., 2007).

E-Cadherin is lost in nearly all forms of epithelial cancers (Christofori and Semb, 1999), and its loss generally increases rather than decreases cell proliferation (Tinkle et al., 2004; Liu et al., 2006; Perrais et al., 2007). Here, we show that this same protein underlies an opposite role in SCs. Such differences shed light on distinctions between stem and cancer cells that are of fundamental importance in understanding tumorigenesis (Reya et al., 2001).

\section{References}

Alvarez-Buylla A, Lim DA (2004) For the long run: maintaining germinal niches in the adult brain. Neuron 41:683-686.

Alvarez-Buylla A, García-Verdugo JM, Tramontin AD (2001) A unified hypothesis on the lineage of neural stem cells. Nat Rev Neurosci 2:287-293. Bendall SC, Stewart MH, Menendez P, George D, Vijayaragavan K, Werbowetski-Ogilvie T, Ramos-Mejia V, Rouleau A, Yang J, Bossé M, Lajoie G, Bhatia M (2007) IGF and FGF cooperatively establish the regulatory stem cell niche of pluripotent human cells in vitro. Nature 448:1015-1021. 
Bendel-Stenzel MR, Gomperts M, Anderson R, Heasman J, Wylie C (2000) The role of cadherins during primordial germ cell migration and early gonad formation in the mouse. Mech Dev 91:143-152.

Betschinger J, Knoblich JA (2004) Dare to be different: asymmetric cell division in Drosophila, C. elegans and vertebrates. Curr Biol 14:R674-R685.

Boussadia O, Kutsch S, Hierholzer A, Delmas V, Kemler R (2002) E-cadherin is a survival factor for the lactating mouse mammary gland. Mech Dev 115:53-62.

Brawley C, Matunis E (2004) Regeneration of male germline stem cells by spermatogonial dedifferentiation in vivo. Science 304:1331-1334.

Campos LS, Decker L, Taylor V, Skarnes W (2006) Notch, epidermal growth factor receptor, and betal-integrin pathways are coordinated in neural stem cells. J Biol Chem 281:5300-5309.

Cheng A, Tang H, Cai J, Zhu M, Zhang X, Rao M, Mattson MP (2004) Gap junctional communication is required to maintain mouse cortical neural progenitor cells in a proliferative state. Dev Biol 272:203-216.

Christofori G, Semb H (1999) The role of the cell-adhesion molecule E-cadherin as a tumour-suppressor gene. Trends Biochem Sci 24:73-76.

Foty RA, Steinberg MS (2005) The differential adhesion hypothesis: a direct evaluation. Dev Biol 278:255-263.

Gottardi CJ, Wong E, Gumbiner BM (2001) E-cadherin suppresses cellular transformation by inhibiting beta-catenin signaling in an adhesionindependent manner. J Cell Biol 153:1049-1060.

Hitoshi S, Alexson T, Tropepe V, Donoviel D, Elia AJ, Nye JS, Conlon RA, Mak TW, Bernstein A, van der Kooy D (2002) Notch pathway molecules are essential for the maintenance, but not the generation, of mammalian neural stem cells. Genes Dev 16:846-858.

Imai F, Hirai S, Akimoto K, Koyama H, Miyata T, Ogawa M, Noguchi S, Sasaoka T, Noda T, Ohno S (2006) Inactivation of aPKClambda results in the loss of adherens junctions in neuroepithelial cells without affecting neurogenesis in mouse neocortex. Development 133:1735-1744.

Imura T, Kornblum HI, Sofroniew MV (2003) The predominant neural stem cell isolated from postnatal and adult forebrain but not early embryonic forebrain expresses GFAP. J Neurosci 23:2824-2832.

Jin Z, Kirilly D, Weng C, Kawase E, Song X, Smith S, Schwartz J, Xie T (2008) Differentiation-defective stem cells outcompete normal stem cells for niche occupancy in the Drosophila ovary. Cell Stem Cell 2:39-49.

Kai T, Spradling A (2003) An empty Drosophila stem cell niche reactivates the proliferation of ectopic cells. Proc Natl Acad Sci USA 100:4633-4638.

Kai T, Spradling A (2004) Differentiating germ cells can revert into functional stem cells in Drosophila melanogaster ovaries. Nature 428:564-569.

Karpowicz P, Morshead C, Kam A, Jervis E, Ramunas J, Ramuns J, Cheng V, van der Kooy D (2005) Support for the immortal strand hypothesis: neural stem cells partition DNA asymmetrically in vitro. J Cell Biol 170:721-732.

Kippin TE, Martens DJ, van der Kooy D (2005) p21 loss compromises the relative quiescence of forebrain stem cell proliferation leading to exhaustion of their proliferation capacity. Genes Dev 19:756-767.

Kuo CT, Mirzadeh Z, Soriano-Navarro M, Rasin M, Wang D, Shen J, Sestan N, Garcia-Verdugo J, Alvarez-Buylla A, Jan LY, Jan YN (2006) Postnatal deletion of Numb/Numblike reveals repair and remodeling capacity in the subventricular neurogenic niche. Cell 127:1253-1264.

Larue L, Ohsugi M, Hirchenhain J, Kemler R (1994) E-cadherin null mutant embryos fail to form a trophectoderm epithelium. Proc Natl Acad Sci U S A 91:8263-8267.

Larue L, Antos C, Butz S, Huber O, Delmas V, Dominis M, Kemler R (1996) A role for cadherins in tissue formation. Development 122:3185-3194.

Lien WH, Klezovitch O, Fernandez TE, Delrow J, Vasioukhin V (2006) alphaE-catenin controls cerebral cortical size by regulating the hedgehog signaling pathway. Science 311:1609-1612.

Lin H (1997) The tao of stem cells in the germline. Annu Rev Genet 31:455-491.

Liu WF, Nelson CM, Pirone DM, Chen CS (2006) E-cadherin engagement stimulates proliferation via Rac1. J Cell Biol 173:431-441.

Louvi A, Artavanis-Tsakonas S (2006) Notch signalling in vertebrate neural development. Nat Rev Neurosci 7:93-102.
Matsunami H, Takeichi M (1995) Fetal brain subdivisions defined by Rand E-cadherin expressions: evidence for the role of cadherin activity in region-specific, cell-cell adhesion. Dev Biol 172:466-478.

Morshead CM, van der Kooy D (2001) A new "spin" on neural stem cells? Curr Opin Neurobiol 11:59-65.

Morshead CM, Reynolds BA, Craig CG, McBurney MW, Staines WA, Morassutti D, Weiss S, van der Kooy D (1994) Neural stem cells in the adult mammalian forebrain: a relatively quiescent subpopulation of subependymal cells. Neuron 13:1071-1082.

Morshead CM, Craig CG, van der Kooy D (1998) In vivo clonal analyses reveal the properties of endogenous neural stem cell proliferation in the adult mammalian forebrain. Development 125:2251-2261.

Morshead CM, Garcia AD, Sofroniew MV, van der Kooy D (2003) The ablation of glial fibrillary acidic protein-positive cells from the adult central nervous system results in the loss of forebrain neural stem cells but not retinal stem cells. Eur J Neurosci 18:76-84.

Ohlstein B, Kai T, Decotto E, Spradling A (2004) The stem cell niche: theme and variations. Curr Opin Cell Biol 16:693-699.

Okamura D, Kimura T, Nakano T, Matsui Y (2003) Cadherin-mediated cell interaction regulates germ cell determination in mice. Development 130:6423-6430.

Perrais M, Chen X, Perez-Moreno M, Gumbiner BM (2007) E-cadherin homophilic ligation inhibits cell growth and epidermal growth factor receptor signaling independently of other cell interactions. Mol Biol Cell 18:2013-2025.

Rasin MR, Gazula VR, Breunig JJ, Kwan KY, Johnson MB, Liu-Chen S, Li HS, Jan LY, Jan YN, Rakic P, Sestan N (2007) Numb and Numbl are required for maintenance of cadherin-based adhesion and polarity of neural progenitors. Nat Neurosci 10:819-827.

Redies C (2000) Cadherins in the central nervous system. Prog Neurobiol 61:611-648.

Reya T, Morrison SJ, Clarke MF, Weissman IL (2001) Stem cells, cancer, and cancer stem cells. Nature 414:105-111.

Reynolds BA, Tetzlaff W, Weiss S (1992) A multipotent EGF-responsive striatal embryonic progenitor cell produces neurons and astrocytes. J Neurosci 12:4565-4574.

Shimamura K, Takeichi M (1992) Local and transient expression of E-cadherin involved in mouse embryonic brain morphogenesis. Development 116:1011-1019.

Song X, Zhu CH, Doan C, Xie T (2002) Germline stem cells anchored by adherens junctions in the Drosophila ovary niches. Science 296:1855-1857.

Song X, Call GB, Kirilly D, Xie T (2007) Notch signaling controls germline stem cell niche formation in the Drosophila ovary. Development 134:1071-1080.

Steinberg MS, Takeichi M (1994) Experimental specification of cell sorting, tissue spreading, and specific spatial patterning by quantitative differences in cadherin expression. Proc Natl Acad Sci U S A 91:206-209.

Takeichi M (1995) Morphogenetic roles of classic cadherins. Curr Opin Cell Biol 7:619-627.

Tinkle CL, Lechler T, Pasolli HA, Fuchs E (2004) Conditional targeting of E-cadherin in skin: insights into hyperproliferative and degenerative responses. Proc Natl Acad Sci U S A 101:552-557.

Tronche F, Kellendonk C, Kretz O, Gass P, Anlag K, Orban PC, Bock R, Klein R, Schütz G (1999) Disruption of the glucocorticoid receptor gene in the nervous system results in reduced anxiety. Nat Genet 23:99-103.

Tropepe V, Sibilia M, Ciruna BG, Rossant J, Wagner EF, van der Kooy D (1999) Distinct neural stem cells proliferate in response to EGF and FGF in the developing mouse telencephalon. Dev Biol 208:166-188.

Ward EJ, Shcherbata HR, Reynolds SH, Fischer KA, Hatfield SD, RuoholaBaker H (2006) Stem cells signal to the niche through the Notch pathway in the Drosophila ovary. Curr Biol 16:2352-2358.

Yamashita YM, Jones DL, Fuller MT (2003) Orientation of asymmetric stem cell division by the APC tumor suppressor and centrosome. Science 301:1547-1550. 